\title{
Os usos das grutas na Idade do Ferro da Baixa Estremadura (Portugal): uma primeira visão de conjunto
}

\section{The uses of caves in the Iron Age of the Lower Estremadura (Portugal): a preliminary overview}

\author{
FRANCISCO B. GOMES \\ UNIARQ - Centro de Arqueologia da Universidade de Lisboa \\ Faculdade de Letras da Universidade de Lisboa \\ Fundação para a Ciência e Tecnologia \\ Alameda da Universidade, 1600-214 \\ Lisboa (Portugal) \\ franciscojbgomes@gmail.com \\ https://orcid.org/0000-0003-0664-6374
}

\section{Resumo}

Nos últimos anos, o desenvolvimento da actividade arqueológica na área da Baixa Estremadura (Penínsulas de Lisboa e Setúbal, Portugal), somada à revisão de conjuntos resultantes de escavações antigas, tem vindo a revelar a existência de um número significativo de cavidades cársicas ocupadas durante a Idade do Ferro. Apresenta-se aqui um primeiro estudo de conjunto dessas ocupações, assente num inventário crítico que permite afirmar que parte significativa das mesmas se terá relacionado com funções religiosas, nas quais a prática de oferendas e o comensalismo ocuparam um lugar fulcral. As pautas cultuais ilustradas pelos materiais recoIhidos nestas grutas parecem evidenciar uma confluência entre tradições com raízes no Bronze Final regional e práticas de origem nitidamente mediterrânea. A posição destas grutas no território sugere uma íntima relação com o mar e a navegação, ao passo que os ritmos de ocupação das mesmas, com um nítido pico em torno a meados do I milénio a. n. e., poderia relacionar-se com lógicas de estruturação do território dinamizadas pelos principais centros políticos regionais.

Palavras-chave: grutas, Idade do Ferro, Baixa Estremadura, práticas rituais, religiosidade

\section{Abstract}

In recent years, the development of archaeological activity in the Lower Estremadura region (Lisbon and Setúbal Peninsulas, Portugal), together with the revision of assemblages retrieved in older excavations, have revealed the existence of a significant number of karstic cavities occupied during the Iron Age. A preliminary overview of those occupations is presented here, based on a critical inventory which shows that a significant part of them relates to religious functions in which the making of offerings and the practice of commensality played a critical role. The cultic praxis illustrated by the material retrieved in these caves seem to highlight a confluence between traditions with roots in the regional Late Bronze Age and practices with a clear Mediterranean origin. The position of these caves in the landscape suggests a close connection to the sea and seafaring, while their oc-

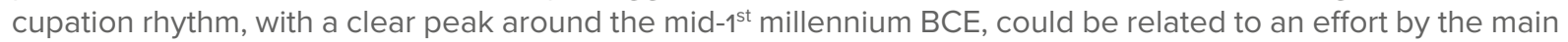
regional political centres to structure their territory.

Key words: Caves, Iron Age, Lower Estremadura, Ritual Practices, Religiosity 
1. Os usos das grutas na Idade do Ferro da Baixa Estremadura: considerações prévias

A crescente intensificação da investigação sobre a Idade do Ferro no Sul do actual território português, assente quer em novos trabalhos de campo quer no estudo e valorização de colecções resultantes de trabalhos antigos, tem permitido nos últimos anos acrescentar abundantes dados novos ao quadro de referência anteriormente disponível.

Assim, e além de nova informação sobre sítios, regiões e temáticas cuja caracterização já se havia esboçado ao longo das décadas finais do século $\mathrm{xx}$ (vid. Arruda, 2013), assistiu-se à incorporação no discurso sobre este período histórico de novas áreas regionais, como a de Beja (cf. Jiménez Ávila, 20I7), cuja real importância era até recentemente insuspeitada. Noutras regiões, como é o caso do Estuário do Tejo (Arruda et alii, 20I7), a investigação permitiu acrescentar novos sítios a redes de povoamento de que já se conheciam alguns nodos, revelando assim uma tessitura mais intrincada e complexa do que a anteriormente conhecida.

Finalmente, há também a assinalar a crescente documentação de novas tipologias de ocupação do território escassamente conhecidas e valorizadas em etapas anteriores da investigação. O estudo do uso das cavidades cársicas enquadra-se nesta última alínea, afigurando-se como um aspecto que, apesar de um notável acréscimo ao nível dos conhecimentos disponíveis, carece ainda de uma visão preliminar de conjunto, lacuna que o presente contributo visa suprir.

É certo que a presença de materiais enquadráveis na Idade do Ferro em ambientes cársicos não constitui exactamente uma novidade, tendo já sido pontualmente assinalada desde pelo menos os finais do século xx (Carreira, 1990-2; Cardoso, 2000; 2004: 295-296). Não obstante, recentes estudos dedicados quer a colecções resultantes de trabalhos antigos (Arruda e Cardoso, 2013; Cardoso, 2013) quer a contextos de identificação mais recente (AA.VV., 20o9; Calado et alii, 20I3; Calado et alii, 20I7; Jiménez Ávila et alii, 2018) permitem hoje compreender que este tipo de ocorrência terá sido mais frequente do que anteriormente se entrevia (Arruda, 20I7: 286-287). Este facto confere um novo significado aos dados anteriormente publicados, significado esse que importa analisar e discutir.

Tendo em mente este objectivo, o presente estudo recolhe os contextos em gruta da Idade do Ferro conhecidos numa área restrita, correspondente ao actual Distrito de Lisboa e à parte setentrional do Distrito de Setúbal, a chamada Península de Setúbal (figura I). A opção pelo tratamento desta área concreta resulta de três critérios fundamentais: I) a concentração de ocorrências do tipo em estudo nestas áreas; 2) a relativa consistência da documentação sobre elas publicada; e 3) a aparente coerência que apresentam entre si, e que leva a pensar numa fórmula de uso das cavidades cársicas que, ainda que não necessariamente unitária, releva de um fundo cultural comum.

É certo que esta opção metodológica exclui à partida outras regiões onde também se parece verificar uma utilização significativa das cavidades cársicas durante a Idade do Ferro, como é o caso da Serra d'Aire e Candeeiros (Tente e Lourenço, 20I6) ou do Vale do Nabão (Félix, 1993). O carácter apesar de tudo mais disperso da documentação disponível para estas áreas, bem como o facto de a mesma evidenciar traços culturais algo distintos dos das regiões estudadas - resultantes, entre outros aspectos, da sua natureza aparentemente mais tardia - justificam a sua não inclusão no presente estudo.

Quanto às eventuais incidências do território algarvio, onde está perfeitamente documentada a existência de sistemas cársicos com importantes ocupações humanas, de que se poderiam destacar, neste contexto, as do Bronze Final (Gomes e Calado, 2007), a informação disponível é virtualmente inexistente, não justificando a sua inclusão no presente estudo.

É assim expectável que no futuro os dados e leituras aqui apresentados - que, no caso de alguns dos sítios recolhidos, serão seguramente incrementados a curto prazo - possam vir a enquadrar-se em leituras de âmbito mais abrangente sobre um aspecto ainda mal conhecido da ocupação do território durante a Idade do Ferro.

Não obstante, a documentação já disponível justifica um primeiro ensaio de ordenação geral e uma leitura de conjunto que contribua para a enquadrar 


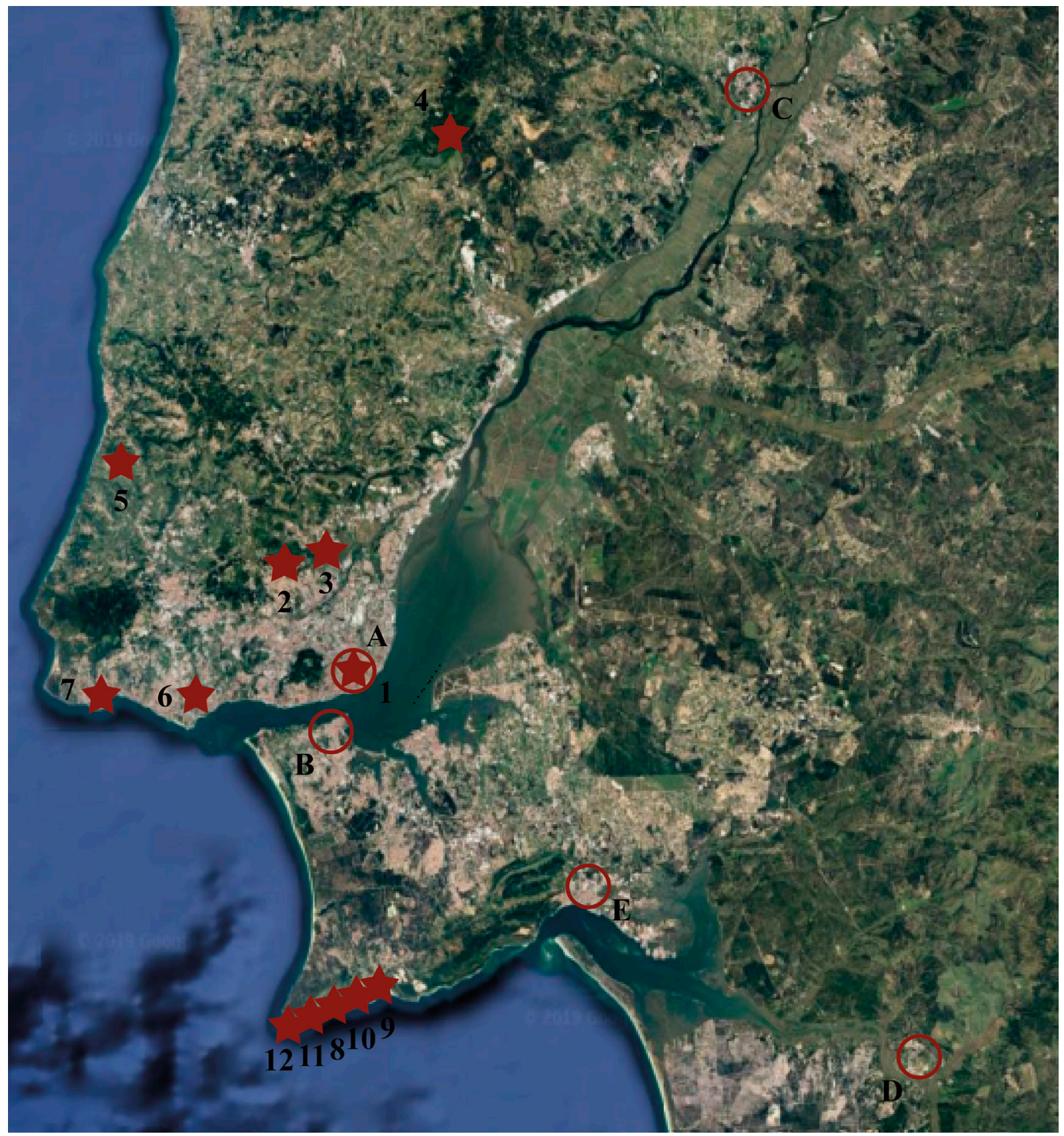

Figura 1. Grutas comentadas no texto (localização aproximada): 1. Rua da Judiaria (Lisboa); 2. Gruta do Correio-Mor (Loures); 3. Lapa da Figueira (Loures); 4. Grutas da Serra de Montejunto (Cadaval); 5. Fojo dos Morcegos (Sintra); 6. Ponte da Lage (Oeiras); 7. Furnas do Poço Velho (Cascais); 8. Lapa do Fumo (Sesimbra); 9. Lapa da Cova (Sesimbra); 10. Forte do Cavalo A (Sesimbra); 11. Janelas I (Sesimbra); 12. Abrigos da Cara do Cabo (Sesimbra). Os círculos assinalam os principais núcleos de povoamento da Idade do Ferro: A. Lisboa; B. Almaraz; C. Santarém; D. Alcácer do Sal; E. Setúbal

Figure 1. Caves mentioned in the text (approximate locations): 1. Rua da Judiaria (Lisbon); 2. Correio-Mor Cave (Loures); 3. Lapa da Figueira (Loures); 4. Serra de Montejunto Caves (Cadaval); 5. Fojo dos Morcegos (Sintra); 6. Ponte da Lage (Oeiras); 7. Furnas do Poço Velho (Cascais); 8. Lapa do Fumo (Sesimbra); 9. Lapa da Cova (Sesimbra); 10. Forte do Cavalo A (Sesimbra); 11. Janelas I (Sesimbra); 12. Cara do Cabo Shelters (Sesimbra). The circles signal the main Iron Age settlements: A. Lisbon; B. Almaraz; C Santarém; D. Alcácer do Sal; E. Setúbal 
no processo histórico deste período na área em apreço. Para esse efeito, elaborou-se um levantamento dos contextos referenciados na bibliografia arqueológica, ainda que, como se verá, a hipótese de uma frequentação durante a Idade do Ferro de alguns deles pareça hoje de excluir.

Esse levantamento resultou num inventário crítico, no qual se procurou sintetizar, para cada um dos sítios analisados, o historial das investigações, a natureza e tipologia do material da Idade do Ferro, a sua cronologia e a sua possível interpretação, por esta ordem. O catálogo assim obtido apresenta-se nas páginas que se seguem.

\section{Catálogo dos contextos em gruta da Idade do Ferro da Baixa Estremadura}

\subsection{A Península de Lisboa}

\subsubsection{Rua da Judiaria (Lisboa)}

A realização em 2009 de uma intervenção arqueológica na Rua da Judiaria, em pleno centro histórico de Lisboa (Calado et alii, 2013) (figura I, n. ${ }^{\circ}$ I), resultou na identificação de uma antiga cavidade cársica. A escavação do seu interior revelou a existência de uma interessante sequência de ocupação datável exclusivamente da I Idade do Ferro (Calado et alii, 20I3).

Além disso, os trabalhos realizados permitiram aferir que durante esse período este espaço corresponderia ainda a uma galeria subterrânea. Com efeito, não se documentaram quaisquer evidências do abatimento do respectivo tecto anteriores ou coetâneas da mencionada ocupação, pelo que presumivelmente o colapso desta gruta terá ocorrido num momento posterior, tendo os vestígios correspondentes sido truncados pela acção construtiva medieval (Calado et alii, 2013: 129).

Já no que diz respeito à sequência documentada no interior deste espaço, foi possível diferenciar dois momentos distintos de ocupação. Nos níveis correspondentes aos momentos mais antigos (Calado et alii, 2013: I26-I27) foram recolhidos tanto grandes recipientes - nomeadamente duas ânforas $\left(\mathrm{Ca}^{-}\right.$ lado et alii, 20I3: fig. 8, n. $^{\circ} 57$ e 92$)$ do tipo Io.I.I.I de J. Ramon Torres (1995) produzidas na Baía de
Cádiz e um pithos com pintura em bandas (Calado et alii, 20I3: fig. 8, n. ${ }^{\circ}$ I88) - como cerâmicas de engobe vermelho - mais concretamente dois pratos de perfil carenado e bordo em aba (Calado et alii, 2013: fig. 8, n. ${ }^{\circ}$ I89) assimiláveis ao tipo P.I.d de Huelva (Rufete Tomico, I988) - e comuns oxidantes - representadas por um prato troncocónico de bordo em aba e por um prato de bordo reentrante (Calado et alii, 20I3: fig. 8, n. ${ }^{\circ} 27$ e I85) (figura 2). Indica-se ainda que estes materiais cerâmicos estariam associados estratigraficamente a restos faunísticos pertencentes a mamíferos (Calado et alii, 20I3: I29).

Por outro lado, foi possível datar uma amostra de carvão exumada num dos níveis associados a esta etapa de ocupação. Infelizmente, o intervalo cronológico obtido é bastante lato ${ }^{1}$. Os materiais exumados neste nível, nomeadamente os recipientes anfóricos e os pratos de engobe vermelho, sugerem contudo um momento de ocupação relativamente antigo dentro da Idade do Ferro regional, datado pelos responsáveis do estudo do conjunto da segunda metade do século viII a.n.e. (Calado et alii, 20I3: I29), embora outros autores tenham já sugerido uma cronologia mais tardia, não anterior ao final do século vil a.n.e. (Sousa, 20I5: II4).

Já no que diz respeito ao segundo momento de ocupação, parece importante assinalar a presença de uma área de combustão no interior deste espaço. $\mathrm{O}$ nível de ocupação associado continha um abundante espólio cerâmico (figura 2), repetindo-se os contentores anfóricos (Sousa, 2015: 123) - desta feita dois exemplares classificados pelos autores do seu estudo nos T. Io.I.2.I ou I0.2.I.I de J. Ramon Torres (1995) e identificados como produções da região de Málaga e os pithoi, representados nesta etapa por dois exemplares (Calado et alii, 2013: fig. 6, n. ${ }^{\circ} 356$ e 368 ).

O repertório das cerâmicas «de mesa» é mais vasto neste segundo momento de ocupação. Assim, e embora a cerâmica de engobe vermelho esteja ausente, verifica-se a presença de diversos recipientes de cerâmica comum e pintada, essencialmente

1 Obteve-se uma datação de $2570 \pm 90 \mathrm{BP}$, o que após calibração a $2 \sigma$ aponta para uma data de $850-4 I$ a.n.e. (intervalo de confiança de 98\%) (Calado et alii, 2013: I26). 


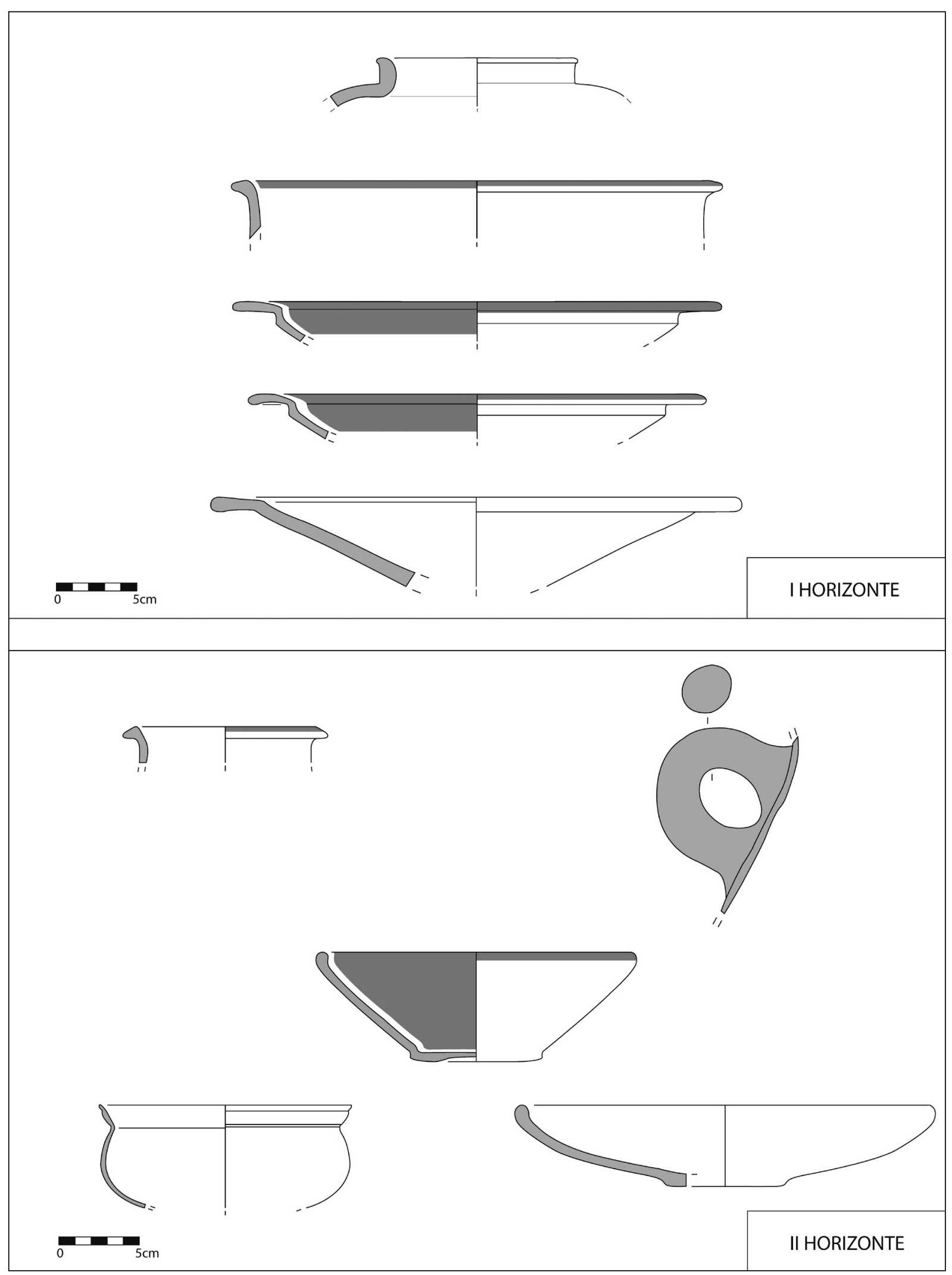

Figura 2. Selecção de materiais da Rua da Judiaria (segundo Calado et alii, 2013, adaptado)

Figure 2. Selected materials from Rua da Judiaria (after Calado et al., 2013, adapted) 
pratos/páteras (Calado et alii, 20I3: fig. 6), bem como exemplares de cerâmica cinzenta (Calado et alii, 20I3: fig. 6, n. ${ }^{\circ} 253$, 30I e 578), correspondentes a taças de perfil arredondado e bordo curto extroverso, assimiláveis aos grupos $3 \mathrm{a}$ e $3 \mathrm{~b}$ definidos para o conjunto da Sé de Lisboa (Arruda, Freitas e Vallejo Sánchez, 20oI). Recolheu-se igualmente um único cossoiro de morfologia discoidal (Calado et alii, 20I3: fig. 6, n. $\left.{ }^{\circ} 545\right)$.

Estes materiais encontravam-se uma vez mais associados estratigraficamente a restos faunísticos, tanto mamalógicos como malacológicos, ao que tudo indica presentes em quantidades significativas (Calado et alii, 2013: 129). Por outro lado, recolheram-se amostras de carvões tanto na estrutura de combustão como no nível associado que foram objecto de datações radiométricas, resultando uma vez mais, em ambos os casos, em intervalos cronológicos relativamente amplos ${ }^{2}$.

Não obstante, e tomando em consideração a cronologia dos materiais antes mencionados, os responsáveis do estudo desta sequência dataram este segundo momento de ocupação da segunda metade do século vi a.n.e. (Calado et alii, 2013: I29), cronologia consentânea com o panorama da cultura material sidérica da restante área de Lisboa (cf. Sousa, 2016: I73-I777; vid. et. Sousa, 20I5: II4).

Caberia finalmente mencionar a existência de um terceiro horizonte estratigráfico, infelizmente muito perturbado por acções construtivas medievais e posteriores. Entre os materiais recolhidos neste nível contam-se novamente os contentores anfóricos, nomeadamente duas asas de ânfora(s) de produção malagueña (Calado et alii, 2013: n. ${ }^{\circ} \mathrm{I}_{2}$ e 486 ) atribuídas a recipiente(s) do T. Io.I.2.I ou T. Io.2.I.I de J. Ramon Torres (1995) e um bordo correspondente a uma produção da Baía de Cádiz e atribuído ao T. II.2.I.2 do mesmo autor (Calado et alii, 20I3: 427).

2 Para a estrutura de combustão obteve-se uma datação de $2350 \pm 60 \mathrm{BP}$, cuja calibração a $2 \sigma$ oferece resultados dispersos, embora com um intervalo de maior confiança (c. $78 \%)$ entre 594 e 35r a.n.e. (Calado et alii, 20I3: I25). Para o nível associado a datação obtida foi de $2390 \pm 50 \mathrm{BP}$, que uma vez calibrada a $2 \sigma$ oferece um intervalo de maior confiança (c. $80 \%)$ entre 595 e 387 a.n.e. (Calado et alii, 2013: I23).
Repetem-se também os pithoi com e sem pintura em bandas (Calado et alii, 20I3: fig. 4), bem como os pratos de cerâmica comum e pintada (Calado et alii, 2013: fig. 4, n. ${ }^{\circ}$ I25 e I66) e os potes de cerâmica comum (Calado et alii, 2013: fig. 4 , n. ${ }^{\circ}$ 510; fig. 5, n. ${ }^{\circ} 452$, 459 e 468). Recolheu-se igualmente um segundo cossoiro, neste caso de morfologia bitroncocónica (Calado et alii, 2013: fig. 5, 403). A cerâmica de engobe vermelho é também rara neste horizonte, estando ainda assim representada por uma taça carenada com bordo vertical recto (Calado et alii, 20I3: fig. 4, n. ${ }^{\circ}$ I86), assimilável ao tipo VIIIb de I. Negueruela (1979). Quanto à cerâmica cinzenta, contam-se dois exemplares adicionais de taças (Calado et alii, 20I3: fig. 5, 406 e 482) do já referido tipo 3 b da Sé de Lisboa (Arruda, Freitas e Vallejo Sánchez, 200I).

Assim, e com a excepção do recipiente de engobe vermelho que poderia sugerir cronologias mais recuadas ( $c f$., por exemplo, os exemplares de Abul A [Mayet e Silva 2000]), o panorama da cultura material deste nível pode considerar-se grosso modo consentâneo com o dos estratos da segunda fase de uso antes comentados.

No que diz respeito à interpretação funcional deste espaço, caberia realçar, na esteira dos responsáveis do seu estudo, quer o seu enquadramento num âmbito crescentemente urbanizado (Calado et alii, 2013: II9; cf. et. Sousa, 20I6), quer a matriz cultural dos materiais ali exumados, que evidenciam desde momentos precoces uma marcada influência mediterrânea, estando nomeadamente ausentes, apesar da antiguidade dos níveis iniciais, os materiais de tradição indígena (Calado et alii, 2013: 129-130).

A estes dois aspectos, que evidenciam uma certa excepcionalidade no uso desta gruta, soma-se a própria natureza dos materiais exumados, onde a combinação de grandes recipientes de natureza destacada (ânforas importadas e pithoi decorados) com recipientes destinados ao consumo de alimentos e bebida, entre os quais se destacam as produções de engobe vermelho, sugere a existência de práticas de consumo alimentar com um carácter particular.

Este panorama, somado à existência de abundantes restos faunísticos em ambos os horizontes 
e de uma área de combustão na fase mais avança$\mathrm{da}$, poderia sugerir que esse consumo se revestiria de um cariz ritualizado, associado a eventuais práticas sacrificiais.

\subsubsection{Gruta do Correio-Mor (Loures)}

Identificada em 1974 como consequência da actividade de uma pedreira, a hoje desaparecida Gruta do Correio-Mor, em Loures (figura I, n. ${ }^{\circ}$ 2), foi objecto de uma escavação de emergência conduzida por uma equipa orientada por Octávio da Veiga Ferreira e Georges Zbyszewski durante a qual se documentou uma importante sequência de ocupação (Cardoso et alii, 2003). Merecem nomeadamente destaque os horizontes do Paleolítico (Ferreira et alii, 1987; Cardoso et alii, 2003: 231-232), do Neolítico e do Calcolítico (Cardoso, 1995; Cardoso et alii, 2003: 232-255), e bem assim da Idade do Bronze (Cardoso, 1997-8; 2003: 255-260).

Estas intervenções resultaram ainda na recolha de um conjunto reduzido mas expressivo de materiais claramente atribuíveis à Idade do Ferro, já publicados em diversas ocasiões (Cardoso, 2000; Cardoso et alii, 2003: 260-26r e figuras 33 e 60-6r; Cardoso, 2004: 295-296 e figuras 233-234).

A maioria desses materiais corresponde a recipientes cerâmicos (figura 3), nomeadamente a peças de cerâmica cinzenta fina, representada por dois pratos (Cardoso et alii, 2003: fig. 60, I-2), uma taça carenada de colo alto e ressalto médio (Cardoso et alii, 2003: fig. 60, 3) e um jarro de asa bífida (Cardoso et alii, 2003: fig. 60, 4), e de cerâmica comum oxidante, representada por uma taça carenada (Cardoso et alii, 2003: fig. 6I, 4), um pote/panela (Cardoso et alii, 2003: fig. 6o, 5) e um grande recipiente de bordo extroverso sub-horizontal (Cardoso et alii, 2003: fig. 6I, 2). Regista-se ainda a presença de um contentor anfórico (Cardoso et alii, 2003: fig. 6I, I) assimilável ao Tipo 6 definido para as produções pré-romanas do Tejo (Sousa e Pimenta 20I4: 308-3II). Documentou-se ainda a presença de duas facas afalcatadas de ferro (Cardoso et alii, 2003: fig. 33, n. ${ }^{\circ}$ 6-7) (figura 3), assimiláveis aos Tipos I e 2 definidos para as peças da necrópole de Medellín (Lorrio, 2008).
Do ponto de vista cronológico, todos estes elementos parecem apontar para um período de uso desta cavidade cársica centrado em torno aos meados do I milénio a.n.e., sendo muito provável que a maioria dos materiais referidos se reporte ao século $v$ a.n.e. Não se pode contudo excluir que algumas destas peças possam ser ligeiramente mais antigas ou mais tardias.

Finalmente, caberia tecer algumas considerações de ordem funcional sobre estes materiais e a utilização sidérica da Gruta do Correio-Mor que materializam. Ao nível do material cerâmico, cabe salientar a presença de recipientes de armazenagem associados a outros claramente destinados ao consumo de alimentos e bebidas, entre os quais se destaca o já mencionado jarro de cerâmica cinzenta fina.

Se a este panorama se somam as duas facas afalcatadas, objectos cujo eventual uso sacrificial se encontra bem documentado noutros contextos (Arruda et alii, 20I7), parece lícito pensar que nos encontramos ante uma panóplia relacionada com a realização de oferendas, já sejam elas cruentas ou incruentas, e eventualmente com práticas de consumo ritualizado de alimentos e bebidas. Esta hipótese coaduna-se bem com a hipótese já levantada pelos responsáveis do estudo desta gruta de que este episódio de utilização da cavidade se tenha revestido, também ele, de um carácter ritual (Cardoso et alii, 2003: 262).

\subsubsection{Lapa da Figueira (Loures)}

A existência de materiais da Idade do Ferro na Lapa da Figueira (Bucelas, Loures) (figura I, n. ${ }^{\circ}$ 3), detectada ao que tudo indica na sequência de recolhas de superfície, encontra-se unicamente referenciada na Carta Arqueológica do Concelho de Loures (Oliveira et alii, 2000: 47). Infelizmente, contudo, os elementos respeitantes ao referido horizonte da Idade do Ferro não foram ainda objecto de publicação, desconhecendo-se portanto as características específicas do material ali recolhido. Por extensão, os parâmetros cronológicos, culturais e funcionais do uso da Lapa da Figueira durante a Idade do Ferro são igualmente desconhecidos. A sua inclusão na lista das grutas utilizadas durante este período deve portanto ser mantida sob reserva. 


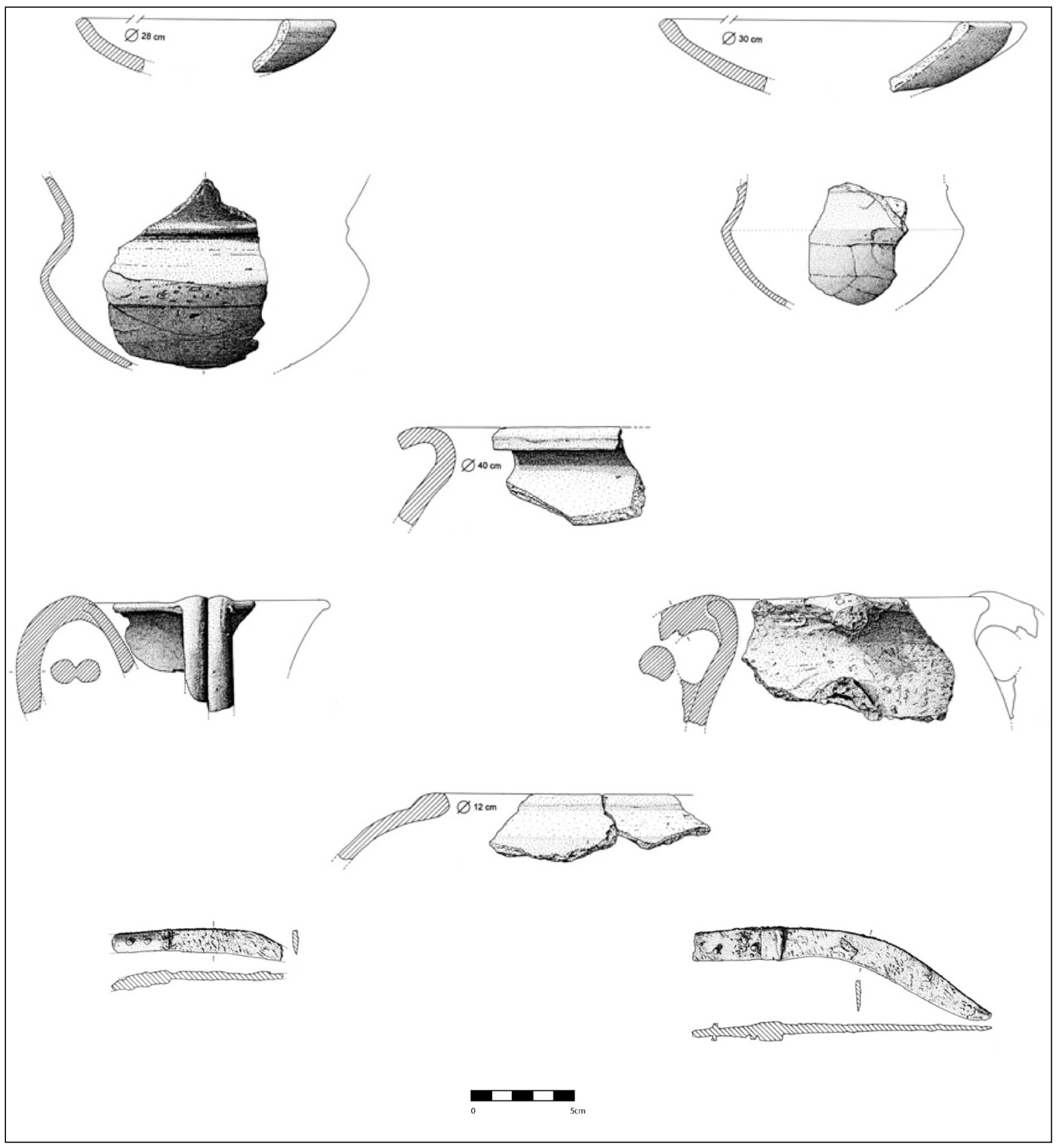

Figura 3. Materiais da Idade do Ferro da Gruta do Correio-Mor (segundo Cardoso et alii, 2003)

Figure 3. Iron Age materials from the Correio-Mor Cave (after Cardoso et al., 2003)

\subsubsection{Grutas da Serra de Montejunto (Cadaval)}

O interesse arqueológico das numerosas cavidades cársicas da Serra de Montejunto (Cadaval) (figura I, n. ${ }^{\circ}$ ) foi precocemente reconhecido ( $c f$. Gonçalves, 1990-1992: 43-44). Os primeiros trabalhos arqueológicos realizados nestas grutas datam com efeito da década de I880, tendo eventualmente chamado a atenção de José Leite de Vasconcelos para as mesmas. O futuro fundador do Museu Ethnologico realizaria com efeito, a partir de 1887 , explorações em várias grutas desta serra, as quais contudo nunca foram sistematicamente publicadas (Gonçalves, 1990-1992: 43-44).

Posteriormente, os sistemas cársicos da Serra de Montejunto seriam novamente objecto de investigação arqueológica, já durante a década de I930, desta feita sob a responsabilidade de Leonel Trindade (Gonçalves, I990-I992: 43-44). A aquisição da 
colecção deste investigador pelo Museu Etnológico do Dr. Leite de Vasconcelos (futuro Museu Nacional de Arqueologia) nos inícios da década seguinte daria ainda origem, ao que parece, a novas investigações em várias grutas sob a égide do director desta instituição, Manuel Heleno, também elas nunca divulgadas (Gonçalves, 1990-1992: 43-44).

Assim, os materiais recolhidos nestes diversos episódios de investigação e depositados naquela instituição só seriam publicados, já nos inícios da década de I990, por João Ludgero Marques Gonçalves (1990-1992). No estudo de conjunto realizado por este investigador, além da extensa documentação respeitante às ocupações Neolíticas, Calcolíticas e da Idade do Bronze, assinalaram-se também algumas incidências tentativamente datadas da Idade do Ferro, que apesar do seu carácter problemático merecem alguns comentários neste contexto.

Em primeiro lugar, caberia referir a Gruta das Lapas (Pragança, Cadaval), onde a putativa ocupação da Idade do Ferro se encontraria documentada por um único cossoiro cerâmico (Gonçalves, I990-I992: $6 \mathrm{e}$ fig. 4 , n. ${ }^{\circ}$ 3). A atribuição deste elemento ao horizonte cronológico em apreço não pode, contudo, considerar-se suficientemente segura.

Com efeito, e se é certo que os cossoiros são particularmente frequentes na Idade do Ferro do Sul de Portugal (Pereira, 2013; Gomes, 2018), a sua presença em contextos pré-históricos, nomeadamente calcolíticos, está também bem atestada (Cardito Rollán, I996). Assim, e dado que desta gruta provêm igualmente materiais atribuíveis a este outro período cronológico, não seria impossível associar o cossoiro em questão às ocupações pré-históricas da gruta.

Igualmente problemáticas são as evidências da Gruta do Mendes (Pragança, Cadaval), onde se recuperou um pequeno conjunto de elementos atribuídos a uma ocupação do Bronze Final ou da Idade do Ferro (Gonçalves, I990-I992: 50). Neste caso, a dificuldade reside na indefinição tipológica dos próprios materiais: um fundo plano correspondente a um grande recipiente (não se indicando a sua técnica de fabrico), um alfinete de bronze com cabeça de secção triangular dupla e uma argola simples, também de bronze (Gonçalves, 1990-I992: fig. I5, n. ${ }^{\circ}$ I3-5). Como bem se reconheceu no estudo citado, nenhuma destas peças se pode considerar como elemento diagnóstico, pelo que, uma vez mais, não se pode demonstrar cabalmente a existência de uma ocupação da Idade do Ferro na gruta em apreço.

Mais clara é a situação da gruta designada Covão das Pias (Gonçalves, I990-I992: 5I). Nesta gruta foi recolhido um fragmento cerâmico decorado que se adscreveu à Idade do Ferro (Gonçalves, I990-I992: fig. I9, n. ${ }^{\circ}$ 2), mas que parece na realidade corresponder a uma peça decorada com ornatos brunidos, atribuível portanto com toda a probabilidade ao Bronze Final.

Finalmente, restaria comentar o caso da Gruta da Fórnea (Lamas, Cadaval) (Gonçalves, I990-1992: I27-I29). Também aqui se propôs ter existido uma ocupação do período em apreço, a qual se encontraria contudo documentada por apenas duas peças (Gonçalves, 1990-I992: 129). A primeira (Gonçalves, 1990-I992: fig. $7 \mathrm{I}, \mathrm{n}^{\circ}{ }^{ }$) corresponde uma vez mais a um fragmento decorado com ornatos brunidos, pelo que se aplicam as mesmas considerações tecidas sobre a peça do Covão das Pias.

Contudo, a segunda peça (Gonçalves, I990-I992: fig. $\left.7 \mathrm{I}, \mathrm{n} .^{\mathrm{o}} \mathrm{I}\right)$, um bordo extroverso de um pote de grandes dimensões, conta efectivamente com paralelos no repertório material da Idade do Ferro regional (Sousa, 20r4: I73); trata-se, não obstante, de uma morfologia relativamente recorrente, também documentada no Bronze Final. Desta forma, e na ausência de dados concretos sobre a técnica de fabrico do mesmo, a sua adscrição cronológica é, também ela, insegura.

Assim, e como ficou evidenciado, a hipótese da existência de utilizações pontuais das grutas da Serra de Montejunto durante a Idade do Ferro não parece suficientemente documentada. A natural evolução do conhecimento sobre a cultura material proto-histórica da região estremenha nas últimas décadas permite, com efeito, repensar, ou pelo menos pôr em dúvida, a cronologia sidérica dos materiais antes referenciados.

\subsubsection{Fojo dos Morcegos (Sintra)}

Identificada enquanto sítio arqueológico em I958, a gruta do Fojo dos Morcegos (Assafora, Sintra) (figura I, n. ${ }^{\circ}$ ) foi explorada em condições particularmente complexas, o que ditou a perda irreversível 
dos dados contextuais e estratigráficos relativos às ocupações desta cavidade cársica. Gustavo Marques, que participou nas primeiras intervenções no sítio, em I958, e que em I965 ali realizaria novos trabalhos de cariz mais sistemático, assumiu o encargo de reunir a parca informação arqueológica disponível, tendo dado à estampa uma nota que constitui o único elemento de juízo disponível para abordar as ocupações antigas da gruta (Marques, I97I).

Neste contributo, além de constatar a presença de ocupações pré-históricas, do Paleolítico e do Calcolítico, este investigador assinala também uma "Ocupação no Bronze-final e Ferro» (Marques, 1971: 148). Se o primeiro destes períodos parece claramente documentado, nomeadamente pelo achado de fragmentos ostentando decoração de ornatos brunidos, a existência de uma ocupação da Idade do Ferro sugerida por este autor não se encontra claramente atestada.

Com efeito, e se é certo que se menciona a existência de cerâmica a torno, «onde se incluem alguns bordos, fundos planos e asas» (Marques, 1971: 147), parte da qual se associa de forma pouco segura à eventual ocupação da Idade do Ferro (Marques, 1971: 148), a verdade é que estes materiais são apresentados, de forma muito sucinta e indiferenciada, em conjunto com outros atribuídos a ocupações já de época histórica, cuja exacta adscrição cronológica se desconhece.

Assim sendo, e apesar de a hipótese de ter efectivamente existido um horizonte da cronologia em apreço nesta cavidade cársica não poder ser completamente descartada até à realização de uma revisão integral dos espólios ali exumados, a sua inclusão no inventário dos contextos em gruta da Idade do Ferro deve ser mantida sob reserva.

\subsubsection{Ponte da Laje (Oeiras)}

A gruta da Ponte da Laje, em Oeiras (figura I, n. ${ }^{\circ}$ 6), foi identificada ainda durante o século xix enquanto sítio de interesse arqueológico, tendo sido objecto de uma primeira intervenção por parte do General Carlos Ribeiro em I879 ( $c f$. Cardoso, 2013: 590). Posteriormente, já em meados do século xx, esta cavidade cársica foi objecto de novos trabalhos de escavação, desta feita sob a responsabilidade de Octávio da Veiga Ferreira, que conjuntamente com Georges Zbyszewski e Abel Viana publicaria uma primeira nota sobre a sequência de ocupação desta gruta (Zbyszewski, Viana e Ferreira, 1957).

No quadro desta primeira súmula propôs-se a existência de uma ocupação da Idade do Ferro, à qual se atribuíram alguns recipientes cerâmicos, atribuição essa que contudo não foi confirmada por revisões posteriores dos espólios. Com efeito, e na sequência de novas intervenções ali efectuadas em 1993 sob a responsabilidade de João Luís Cardoso (1995), este investigador realizaria uma sistemática revisão dos importantes espólios exumados nesta gruta, cabendo destacar neste contexto, além dos estudos sobre as ocupações paleolíticas (Cardoso, 1995) e calcolíticas (Cardoso, 20I3; 20I4), a análise sistemática dos materiais atribuíveis à Idade do Bronze (Cardoso e Carreira, 1996).

No contexto desta revisão, e como ficou dito, verificou-se que a ocupação da Idade do Ferro não dispunha de uma documentação tão extensa como anteriormente se tinha proposto (Cardoso, 2013: 597; cf. et. Cardoso e Carreira, 1996). Registou-se ainda assim a presença de um fragmento do aro externo de uma fíbula anular hispânica, de tipo indeterminado (Cardoso, 2or3: fig. 9, n. ${ }^{\circ}$ ), que evidencia a existência de uma frequentação pontual deste espaço durante o período em apreço.

Infelizmente, a natureza isolada e pouco característica deste elemento não permite tecer considerações de maior sobre a natureza dessa frequentação. Pode contudo afirmar-se que a mesma não deverá ser anterior aos meados do I milénio a.n.e., momento em que se produz a generalização das fíbulas de tipo anular hispânico.

Por outro lado, caberia assinalar a relativa escassez de elementos de indumentária no conjunto dos contextos em gruta aqui analisados (vid. contudo Carreira, I990-I992; Gonçalves, 2008: I37 e ss.). Não obstante, o cariz marcadamente pontual e isolado da fíbula da Gruta da Ponte da Laje não permite realizar quaisquer inferências de natureza funcional, contrariamente ao que ocorre noutros sítios onde a concentração de elementos de indumentária permite avançar hipóteses de leitura mais consistentes (cf. infra, 2.I.7 e 2.2.2). 


\subsubsection{Grutas do Poço Velho (Cascais)}

As Grutas do Poço Velho, três cavidades cársicas situadas no interior da actual malha urbana de Cascais (figura I, n. ${ }^{\circ}$ ), foram identificadas enquanto sítio arqueológico ainda no século XIX, tendo sido objecto de extensos trabalhos de escavação sob a direcção do General Carlos Ribeiro em I879. As importantes ocupações pré-históricas documentadas durante estes trabalhos só viriam contudo a ser divulgadas já na década de 1940, pela mão de Afonso do Paço (cf. Gonçalves, 2008). Quanto às ocupações das Idades do Bronze e do Ferro, a sua devida valorização é bastante mais tardia, só se tendo verificado já nos inícios dos anos 1990, com a publicação de um estudo de Júlio Roque Carreira (1990-1992) incidindo sobre os materiais proto-históricos ali exumados.

Nesse contributo, e além de uma série de materiais cerâmicos e metálicos que evidenciam a continuidade do uso destas grutas durante o Bronze Pleno e Final, deram-se a conhecer algumas peças claramente atribuíveis à Idade do Ferro (Carreira I990-I992: fig. $2, n .^{\circ} 5^{-6)}$. Entre estas, destaca-se um pequeno conjunto de elementos metálicos, nomeadamente uma fíbula de Tipo «Acebuchal» e o aro exterior de uma fíbula anular hispânica, de tipo indeterminado, o qual preserva ainda uma pequena porção da mola (figura 4).

Posteriormente, e no contexto da revisão sistemática dos espólios oriundos destas grutas realizado sob a responsabilidade de Victor S. Gonçalves (2008), foram ainda identificados alguns elementos adicionais atribuíveis ao horizonte em apreço. Entre estes, e ainda ao nível dos elementos de indumentária, caberia referenciar uma peça de bronze que parece corresponder a um fragmento de um fecho de cinturão do tipo dito "céltico" ostentando decoração de círculos concêntricos (Gonçalves 2008: I38 e figs. 2.I4-2.15), cuja tipologia exacta é contudo impossível de determinar.

Reconheceu-se ainda a presença de alguns recipientes cerâmicos também eles atribuíveis à Idade do Ferro (figura 4). Entre estes caberia destacar um pequeno conjunto de potes de bordo estrangulado (Gonçalves 2008: fig. 2.13), com bons paralelos nos repertórios cerâmicos da Idade do Ferro regional ( $c f$. Sousa, 20I4; 2016). Documentou-se ainda a presença de um pequeno recipiente caliciforme (Gonçalves, 2008: fig. 2.I2), forma que, não sendo comum nos repertórios regionais, conta não obstante com paralelos noutras áreas do Sudoeste Peninsular (Celestino Pérez e Jiménez Ávila, r996: fig. 49).

Finalmente, publicou-se ainda um cossoiro (Carreira, 1990-I992: fig. 3, n. ${ }^{\circ}$ 6; Gonçalves, 2008: fig. 2.I3) que poderia atribuir-se, com reservas, à Idade do Ferro. Tal como já foi mencionado, este tipo de peça é particularmente frequente durante o período em apreço (Pereira, 2013; Gomes, 2018), não devendo contudo esquecer-se que estes elementos também se encontram documentados em contextos do Calcolítico (Carreira, 1990-1992: 24I-242; Cardito Rollán, I996).

Estes materiais, tomados no seu conjunto, parecem indiciar uma utilização deste espaço centrada muito possivelmente no século $\mathrm{v}$ a.n.e., embora não se possa descartar que alguns elementos, como a fíbula de Tipo «Acebuchal», remontem à centúria anterior (cf. Gonçalves, 2008: I38).

Infelizmente, e dada a data recuada da escavação realizada nestas grutas, o contexto específico de proveniência das peças em apreço não pode hoje ser reconstituído. No entanto, caberia assinalar que a natureza dos materiais antes comentados parece distinta da das restantes cavidades cársicas inventariadas, onde os elementos de indumentária são residuais ou, pelo menos, secundários. Com efeito, a presença de um conjunto de peças relacionadas com a vestimenta - fíbulas e fecho de cinturão - , embora não constitua caso único, reveste-se de características distintas das observadas noutras grutas, o que poderia indiciar uma funcionalidade diferenciada para as grutas do Poço Velho, porventura de índole funerária, como já se sugeriu (Cardoso, 2004: 295).

É certo que o uso funerário de cavidades cársicas no Ocidente Peninsular durante a Idade do Ferro não está, de momento, documentado; no entanto, os elementos do tipo aqui assinalado, sem serem deles exclusivos, são uma presença frequente em contextos de necrópole ( $c f$. Gomes, 20I6), onde integrariam a indumentária dos defuntos. O próprio material cerâmico tão-pouco destoaria num ambiente de natureza funerária. 


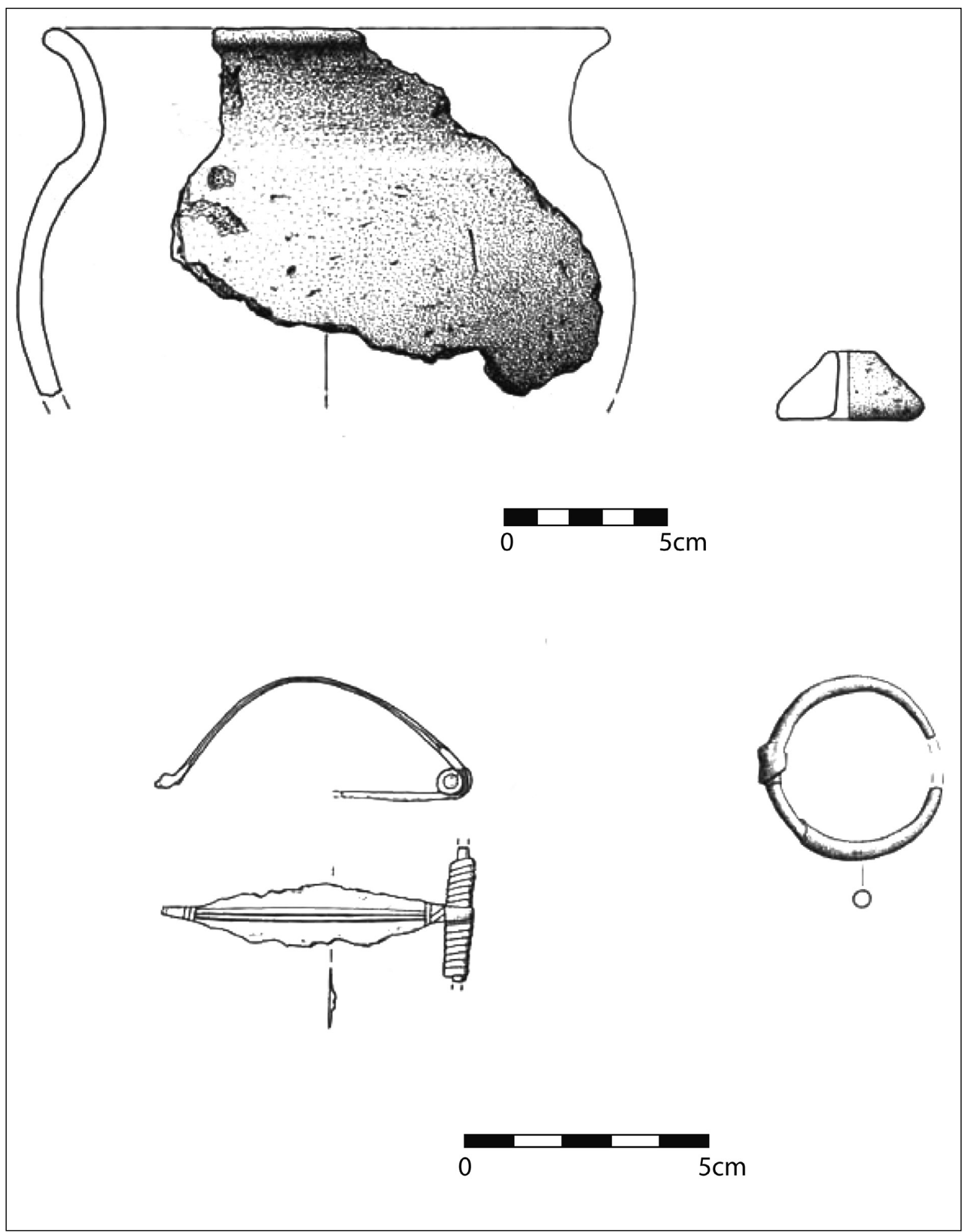

Figura 4. Selecção de materiais da Idade do Ferro das Furnas do Poço Velho (segundo Carreira, 1990-1992)

Figure 4. Selected Iron Age materials from Furnas do Poço Velho (after Carreira, 1990-1992) 
De qualquer forma, a relativa escassez dos espólios parece sugerir, como já se assinalou (Sousa, 20r4: 45), que a utilização deste espaço durante a Idade do Ferro terá sido pontual e, a aceitar-se a sua natureza funerária, excepcional, não tendo dado origem a uma frequentação intensa ou sistemática destas grutas durante o período analisado.

\subsection{A Península de Setúbal}

\subsubsection{Lapa do Fumo (Sesimbra)}

Conhecida pelas suas ocupações pré-históricas ( $c f$. Serrão e Marques, 1971; Serrão, 1975; Cardoso, 2000) e, sobretudo, pelo seu papel na definição de um dos elementos materiais mais característicos do Bronze Final do Sudoeste Peninsular - a cerâmica de ornatos brunidos (Serrão, I96r; vid. et. Cardoso, 1996) a Gruta da Lapa do Fumo, cavidade cársica aberta na vertente meridional da Serra dos Pinheirinhos, em posição sobranceira ao mar (figura I, n. ${ }^{\circ}$ 8), conheceu também uma ocupação significativa durante a Idade do Ferro, até recentemente pouco valorizada.

Com efeito, e apesar de várias referências pontuais de Eduardo da Cunha Serrão e Gustavo Marques, responsáveis pelas escavações realizadas nesta gruta (Serrão e Marques, I971: I23; Serrão, I975: 218; 1994), os materiais correspondentes ao horizonte cronológico em apreço permaneceram virtualmente inéditos até à publicação de um estudo recente (Arruda e Cardoso, 20I3) que permitiu pela primeira vez aferir da real importância dessa ocupação sidérica.

O conjunto de materiais enquadráveis neste período, recolhidos em estratos superficiais relativamente perturbados (Arruda e Cardoso, 2013: 734-736), é com efeito expressivo, compondo-se exclusivamente de recipientes cerâmicos (figura 5). Entre estes, destacam-se os grandes contentores, nomeadamente os pithoi e os recipientes anfóricos (Arruda e Cardoso, 2013: 740-745; figs. 7-II), estando estes últimos representados por peças de aparente produção regional, assimiláveis aos Tipos 2 e 7 da tipologia estabelecida para as produções do Tejo (Arruda e Cardoso, 2013: 740-745; figs. 7-II; $c f$. Sousa e Pimenta, 20I4). Estão também documentados outros recipientes de armazenagem, de tipologia diversa, produzidos tanto a torno como, pelo menos num caso, à mão (Arruda e Cardoso, 2013: 746). Também a recipientes desta natureza pertenceriam sem dúvida os dois fragmentos com decoração estampilhada recolhidos nesta gruta (Arruda e Cardoso, 2013: 746-747 e fig. 6, n. ${ }^{\circ}$ 2-3).

Ao nível das cerâmicas finas destaca-se a presença de uma rara imitação em cerâmica cinzenta de um skyphos ático (Arruda e Cardoso, 2013: 738-740, fig. 6, n. ${ }^{\circ}$; fig. 7, n. $^{\circ}$ 6) bem como de um jarro (Arruda e Cardoso, 20I3: 746 e fig. 7, n. $^{\circ}$ I) tipologicamente similar ao exemplar antes comentado da Gruta do Correio-Mor (vid. supra, 2.I.2).

Do ponto de vista cronológico, e como bem assinalam os responsáveis do estudo deste conjunto (Arruda e Cardoso, 2013: 748), os materiais mencionados parecem indiciar uma ocupação relativamente dilatada no tempo. Com efeito, elementos como os pithoi poderiam remontar aos finais do século vil a.n.e. ou à centúria seguinte, sendo contudo mais frequentes os elementos que caberia adscrever aos séculos v a III a.n.e. (Arruda e Cardoso, 20I3: 748). Infelizmente, a escassa resolução contextual destas peças não permite aferir os eventuais matizes da ocupação deste espaço ao longo deste intervalo aparentemente amplo.

Quanto à leitura funcional destes materiais, assinala-se a repetição de um padrão já observado nas Grutas da Rua da Judiaria e do Correio-Mor (cf. supra, 2.I.I e 2.I.2), com um predomínio de grandes contentores associados a recipientes destinados ao consumo de alimentos e bebida, que assumem nalguns casos uma natureza excepcional (caso do skyphos). Pode assim pensar-se, também aqui, na existência de práticas ritualizadas de consumo que se coadunariam bem com a natureza ritual defendida pelos responsáveis do estudo deste conjunto para a ocupação da Idade do Ferro da Lapa do Fumo (Arruda e Cardoso, 20I3: 748).

\subsubsection{Lapa da Cova (Sesimbra) e outras cavidades cársicas do Maciço da Arrábida}

Além da Lapa do Fumo existem diversas referências à existência de ocupações da Idade do Ferro noutras cavidades cársicas pertencentes às várias formações 


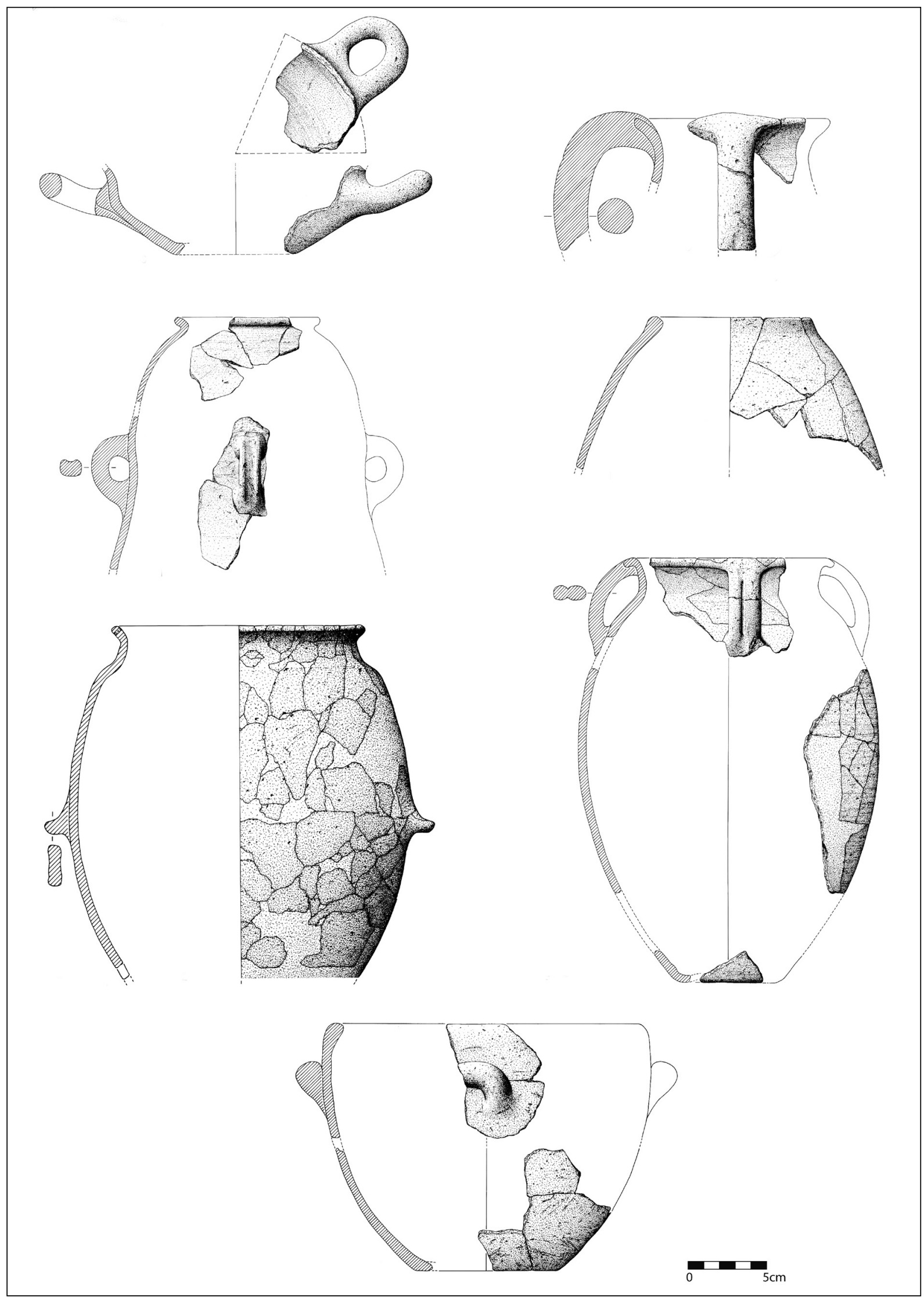

Figura 5. Selecção de materiais da Idade do Ferro da Lapa do Fumo (segundo Arruda e Cardoso, 2013)

Figure 5. Selected Iron Age materials from Lapa do Fumo (after Arruda e Cardoso, 2013) 
que integram o Maciço da Arrábida, a mais significativa das quais é, sem dúvida, a da Lapa da Cova (Sesimbra) (Calado et alii, 20I7; Jiménez Ávila et alii, 20I8; cf. et. AA.VV., 2009) (figura I, n. ${ }^{\circ}$ 9).

A ocupação sidérica desta gruta sobranceira ao mar e dificilmente acessível por via terrestre foi identificada no contexto dos trabalhos de revisão da Carta Arqueológica de Sesimbra (AA.VV., 2009), tendo posteriormente sido comprovada e caracterizada através da realização de escavações arqueológicas das quais se conhecem já alguns resultados preliminares (Calado et alii, 20I7; Jiménez Ávila et alii, 2018).

As intervenções arqueológicas incidiram, por um lado, na parte superior da chamada «sala principal», onde praticamente não se conservavam vestígios arqueológicos à excepção de alguns possíveis restos de uma estrutura de argila ou adobe (Calado et alii, 2017: 530; Jiménez Ávila et alii, 2018: 310), e, por outro, na chamada «sala lateral», que forneceu, ela sim, abundantes vestígios relacionados com a ocupação sidérica da gruta. Com efeito, a escavação realizada nesta pequena cavidade interior permitiu identificar uma estratigrafia rica em restos de combustão, nomeadamente cinzas (Calado et alii, 20I7: 530; Jiménez Ávila et alii, 2018: 3II), pela qual se distribuía um conjunto expressivo de materiais de diversa natureza.

Como em várias das outras cavidades cársicas acima inventariadas, esse conjunto parece ser dominado pelos recipientes cerâmicos, com particular destaque para os contentores anfóricos (Calado et alii, 2017: 536, fig. 4; Jiménez Ávila et alii, 2018: 312, fig. 4) (figura 6), referenciando-se a presença de abundantes ânforas do Tipo B/C de Pellicer (I978) ou talvez mais propriamente dos Tipos I, 4 e 6 recentemente definidos para as produções anfóricas pré-romanas do Tejo (Sousa e Pimenta, 20I4). O momento mais provável de convivência destes três tipos parece enquadrar-se grosso modo no século v a.n.e., datação consentânea, como se verá, com a proposta avançada pelos responsáveis do estudo deste conjunto (Calado et alii, 20I7: 538).

O conjunto inclui ainda um outro exemplar anfórico cujo enquadramento crono-tipológico suscita maiores dúvidas. Como bem assinalam os autores que a dão a conhecer, esta peça, com um bordo espessado internamente, ombro proeminente, três asas trífidas e dotada de decoração pintada (bandas demarcando faixas decoradas com motivos reticulados) (Calado et alii, 20I7: fig. 5; Jiménez Ávila et alii, 2018: fig. 5) (figura 6), poderia relacionar-se, tanto formal como decorativamente, com os contentores anfóricos de tipo Trayamar 2 (Calado et alii, 20I7: 538-539), embora apresente inegáveis particularismos morfológicos. Os responsáveis do seu estudo inclinam-se para a identificação desta peça como uma importação - hipótese que parece, com efeito, muito provável -, datando-a tentativamente dos inícios/ primeira metade do século vi a.n.e. (Calado et alii, 2017: 538-539).

O conjunto cerâmico da Lapa da Cova inclui ainda exemplares enquadráveis noutras produções, nomeadamente um conjunto de cerâmicas cinzentas que inclui tigelas de bordo espessado bem como taças e páteras com carenas bem marcadas (Calado et alii, 20I7: 538, fig. 4, n. ${ }^{\circ} \mathrm{I}-6$ ) (figura 6). Estas últimas merecem um destaque particular, na medida em que correspondem a uma forma particularmente característica da produção vascular do Baixo Tejo (Sousa, 2014: fig. 76), mas também do Baixo Sado (Mayet e Silva, 2000: figs. 65 e 78), a partir do século $v$ a.n.e..

Entre os exemplares cerâmicos ilustrados nos trabalhos já publicados sobre a Lapa da Cova reconhece-se igualmente um pithos com um colo de tendência cónica (Calado et alii, 20I7: fig. 4 , n. ${ }^{\circ}$ I3; Jiménez Ávila et alii, 2018: fig. 4, n.o I3) (figura 6), com paralelos nas peças já mencionadas da Lapa do Fumo (Cardoso e Arruda, 2013), bem como noutros exemplares regionais provenientes de contextos do século vi a.n.e. (Sousa, 20r6: fig. 7; Sousa e Arruda, 20r8: figs. 20 e 22). Finalmente, os autores citados referem ainda a presença de exemplares de cerâmica comum, nomeadamente de recipientes dotados de asas de tamanho médio, de morfologia não especificada (Calado et alii, 20I7: 538).

Se a presença e natureza deste conjunto cerâmico, apesar do seu inegável interesse, é em certa medida comparável ao panorama registado noutras das cavidades cársicas já comentadas, o restante repertório material recolhido durante as intervenções na Lapa da Cova destacam-na claramente dentro do panorama anteriormente esboçado. 


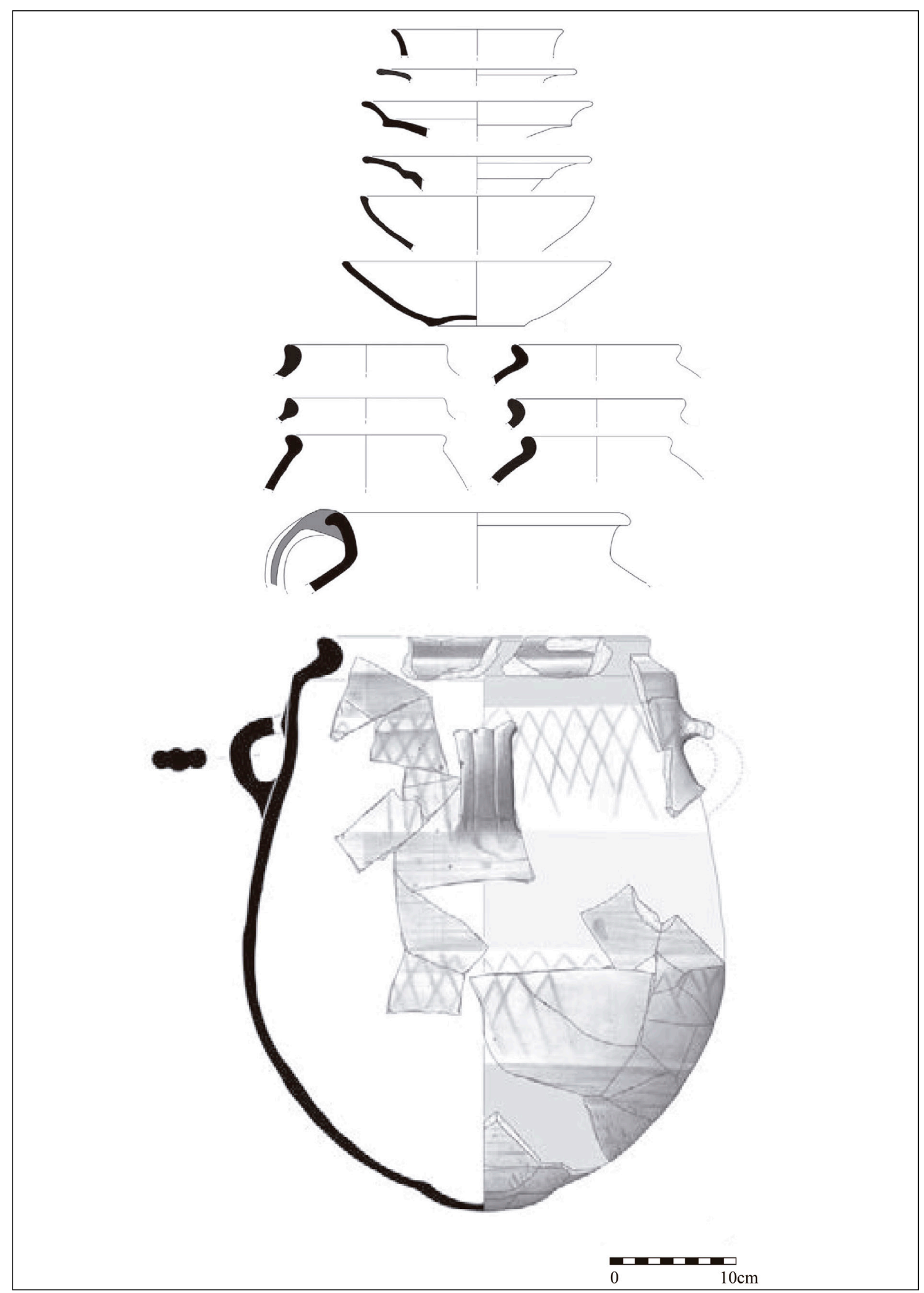

Figura 6. Materiais cerâmicos da Idade do Ferro da Lapa da Cova (segundo Jiménez Ávila et alii, 2018)

Figure 6. Iron Age pottery from Lapa da Cova (after Jiménez Ávila et al., 2018) 
Esse repertório inclui, por um lado, um conjunto de elementos metálicos relacionados com funções quase seguramente rituais e, por outro, um conjunto expressivo e destacado de elementos de adorno e de indumentária. Em relação aos primeiros, caberia destacar a presença de um fragmento da pega em forma de mão pertencente a um recipiente ritual (vulgo «braseiro») de bronze, integrável no Tipo 2 estabelecido por J. Jiménez Ávila (2013) e enquadrável no século $v$ a.n.e., e de parte de um espeto ou obéloi, igualmente de bronze (Calado et alii, 2017: 533-535, fig. 3 , n. ${ }^{\circ}$ I e 4 ). A estes elementos poderia somar-se um botão discoidal com protuberância central cónica, também ele de bronze, com bons paralelos em conjuntos metálicos do Médio Guadiana datados, também eles, do século v a.n.e. (Calado et alii, 20I7: 535).

Quanto aos elementos de adorno, destacam-se no conjunto um brinco e uma arrecada de ouro, esta última com elementos embutidos de âmbar; o primeiro foi recolhido casualmente ainda antes do início dos trabalhos arqueológicos, achado que motivou a realização dos mesmos, ao passo que a segunda foi recuperada já durante as intervenções arqueológicas (Calado et alii, 20I7: 532-533 e fig. 3, n. ${ }^{\circ} 6$ e 7; Jiménez Ávila et alii, 20I8: 3II-3I2 e fig. 3, n. ${ }^{\circ} 6$ e 7).

Como bem assinalam os responsáveis pelo estudo destas peças, ambas apresentam uma filiação técnica e estilística na ourivesaria derivada da mais antiga tradição «orientalizante», podendo o brinco, que não conta com paralelos exactos nos repertórios conhecidos até ao momento, aproximar-se das tradições produtivas dos ateliers de Cádiz e do Mediterrâneo Central (Calado et alii, 20I7: 532; Jiménez Ávila et alii, 20I8: 3II-3I2). A arrecada, por seu turno, integra-se grosso modo num mesmo ambiente crono-cultural, contando, contudo, com um paralelo próximo, já assinalado pelos responsáveis do seu estudo, na Cabeça de Vaiamonte, em Monforte (Correia, Parreira e Silva, 2013: ro6). Ambos os elementos poderiam facilmente enquadrar-se numa cronologia do século $v$ a.n.e..

O conjunto de elementos de adorno exumado durante as escavações da Lapa da Cova engloba ainda um número ao que tudo indica avultado (segundo os dados publicados, mais de uma centena) de contas de colar, de diversas matérias-primas, incluindo contas cilíndricas de materiais líticos, de tonalidade alaranjada (cornalina?), branca, amarela e cinzenta/negra, contas esféricas de vidro, incluindo exemplares monocromos negros e azuis oculados a branco, bem como contas de matérias-primas invulgares, como o âmbar, o osso ou o cristal de rocha (Calado et alii, 20I7: 535-536 e fig. 3, n.o 5; Jiménez Ávila et alii, 20I8: 3I2 e fig. 3, n. ${ }^{\circ}$ 5).

Finalmente, caberia ainda assinalar a referência à presença entre os espólios recuperados durante esta intervenção de fragmentos pertencentes a objectos de adorno e indumentária de bronze, nomeadamente braceletes com extremidades em forma de ofídeo e de fíbulas de dupla mola (Calado et alii, 2017: 535).

Como foi devidamente assinalado pelos responsáveis do estudo da Lapa da Cova, este conjunto material não apresenta balizas cronológicas necessariamente homogéneas, o que poderá indiciar um período de frequentação e utilização desta cavidade cársica relativamente prolongado. Com efeito, alguns elementos, como a ânfora com decoração pintada, o pithos ou as fibulas de dupla mola poderiam evidenciar um início relativamente precoce para o uso desta gruta, possivelmente no século vi a.n.e. (Calado $e t$ alii, 20I7: 540), embora o grosso do material aponte para uma utilização particularmente intensa já durante o século v a.n.e. (Calado et alii, 20I7: 540).

No que diz respeito à interpretação funcional desta gruta no contexto da Idade do Ferro regional, os responsáveis do seu estudo valorizaram a natureza excepcional dos materiais ali recolhidos bem como a sua posição inacessível e intimamente relacionada com o horizonte marítimo, decantando-se claramente por uma interpretação de índole cultual (Calado et alii, 2017: 540-54I).

Já do ponto de vista da restituição das práticas que tiveram lugar dentro deste espaço cársico, convém reter algumas observações transmitidas pelos mesmos autores: em primeiro lugar, o estado muito fragmentário do material recuperado; em segundo lugar, o facto de fragmentos da mesma peça ocorrerem em contextos estratigráficos distintos; em terceiro lugar, o facto de os materiais arqueológicos se encontrarem associados a abundantes restos de combustão (Calado et alii, 2017: 530-53I). 
Em face dessas observações, concluiu-se que esta acumulação de materiais resultaria «[...] de limpiezas y barridos de actividades realizadas en la plataforma superior de la sala principal, y que en estas actividades [tuvo] un destacado papel el fuego» (Calado et alii, 20I7: 531). A «sala lateral» funcionaria assim como uma espécie de botbros no qual se amortizariam os restos das actividades cultuais e das oferendas dedicadas durante essas actividades.

Ao papel do fogo nessas actividades, devidamente destacado pelos autores citados, caberia somar a presença, uma vez mais, de grandes contentores, anfóricos e de outra natureza, de recipientes cerâmicos relacionados com o serviço e consumo da bebida e da comida e inclusivamente de um espeto, podendo todos estes elementos relacionar-se de forma plausível com a prática de rituais de comensalismo. Repetem-se, portanto, na Lapa da Cova determinadas pautas rituais já observadas em vários dos sítios anteriormente referenciados.

A esses rituais poderão ainda ter-se somado outras práticas, nomeadamente a realização de oferendas de elevado valor, sob a forma dos elementos de adorno e indumentária antes comentados, ou a realização de lustrações e/ou libações, evidenciadas pela presença de um «braseiro» de bronze.

Finalmente, antes de encerrar este ponto do inventário, não pode deixar de se mencionar a existência de outras ocupações da Idade do Ferro referenciadas em várias outras grutas e abrigos desta região, nomeadamente na Lapa do Forte do Cavalo A (AA.VV., 2009: IIg) (figura I, n. ${ }^{\circ}$ Io), na Lapa da Janela I (AA.VV., 2009: II5) (Figura I, n. ${ }^{\circ}$ II), e em dois abrigos enquadrados na formação conhecida como Cara do Cabo, no Cabo Espichel (AA.VV., 2009: I05) (figura I, n. ${ }^{\circ}$ I2), todos pertencentes ao concelho de Sesimbra. Infelizmente, os dados relativos às ocupações destas cavidades cársicas são escassos, não permitindo maiores considerações de índole cronológica ou funcional, ainda que uma extensão da natureza ritual da Lapa do Fumo e da Lapa da Cova pareça plausível.

\subsection{Comentário ao catálogo}

Antes de procurar tecer algumas considerações gerais sobre o enquadramento cultural das ocupações em gruta recolhidas nos apartados precedentes, parece importante acrescentar um comentário geral ao catálogo visando sistematizar, mesmo que brevemente, a informação compilada.

Um primeiro aspecto que merece menção diz respeito à relativa frequência das ocupações em gruta da Idade do Ferro na região estudada, aspecto que a priori poderia passar despercebido. Não obstante, e como demonstrado nas páginas anteriores, as referências a incidências deste tipo presentes na bibliografia arqueológica devem ser tratadas de forma crítica, na medida em que a evolução do conhecimento sobre a cultura material proto-histórica do Sul de Portugal permite hoje rever a integração de vários dos sítios estudados (Grutas da Serra de Montejunto, Fojo dos Morcegos) na Idade do Ferro. Noutros casos, como o da Lapa da Figueira, a informação é ainda insuficiente para integrar os sítios numa discussão de âmbito geral como a que se pretendeu desenvolver neste contexto.

Uma segunda nota necessária diz respeito à distribuição cronológica dos sítios analisados, que parece longe de ser homogénea. Com efeito, as ocupações em gruta durante as fases iniciais da I Idade do Ferro (séculos viII-vir a.n.e.) parecem ser, de momento, muito restritas, cingindo-se aos casos da Rua da Judiaria (vid. contudo Sousa, 2015: II4) e possivelmente da Lapa do Fumo.

Pelo contrário, em torno aos meados do I milénio (séculos vi-v a.n.e.) verifica-se uma proliferação de contextos em gruta. Além dos dois sítios antes citados, que permanecem ao que tudo indica ocupados, integram-se igualmente nesta etapa as Grutas do Correio-Mor, da Ponte da Laje e do Poço Velho e a Lapa da Cova, não sendo impossível que as restantes grutas do Maciço da Arrábida antes mencionadas tenham também conhecido ocupações nesta etapa. É possível que esta proliferação se relacione com processos de intensificação da ocupação e exploração do território dinamizadas pelos antigos núcleos «orientalizantes», como Lisboa (cf. Sousa, 20I4) e Alcácer do Sal (Silva et alii, I980-I98I; Silva, 2005; vid. et. Gomes, 2016), no contexto da restruturação das redes sociais, políticas e económicas ocorrida a partir do século vi a.n.e..

Em todo o caso, as ocupações em gruta parecem entrar em marcada retracção durante as etapas finais da II Idade do Ferro (séculos IV-III a.n.e.), havendo a registar unicamente a ocupação continuada da Lapa 
do Fumo. Curiosamente, é precisamente nesta etapa que parece intensificar-se o uso das grutas noutras áreas mais setentrionais, nomeadamente no Maciço da Serra d'Aire e Candeeiros (Tente e Lourenço, 20I6).

Finalmente, um terceiro ponto merecedor de comentários adicionais diz respeito à distribuição funcional das ocupações analisadas, que parecem passíveis de divisão em três grandes grupos.

O Grupo A (Rua da Judiaria, Gruta do Correio-Mor, Lapa do Fumo, Lapa da Cova) engloba ocorrências onde os materiais cerâmicos são predominantes ou, pelo menos, expressivos, registando-se uma associação entre grandes contentores de transporte e armazenagem e recipientes destinados ao serviço e consumo de alimentos e bebidas.

Estes encontram-se, pelo menos nalguns casos (Rua da Judiaria, Lapa da Cova), associados a áreas e/ou restos de combustão e, no caso da Rua da Judiaria, a abundantes restos faunísticos. Já na Gruta do Correio-Mor verifica-se a presença de duas facas afalcatadas que poderiam revestir-se de uma função sacrificial, registando-se ainda na Lapa da Cova a aparente presença de utensilagem de bronze que poderia também estar associada com práticas rituais e de comensalismo.

Todos estes elementos, somados à própria topografia destas ocupações, parecem sugerir um uso eminentemente cultual destes espaços ( $c f$. Cardoso et alii, 2003: 262; Arruda e Cardoso, 2013: 748-749; Calado et alii, 20I7: 540-54I; Jiménez Ávila et alii, 2017: 315), com uma predominância marcada de práticas sacrificiais e um eventual consumo ritualizado de comida e bebida. Como se verá, estas práticas poderão ter-se revestido de um carácter propiciatório relacionado com a prática da navegação e com a sacralização dos acidentes geográficos que serviam de marcadores nas viagens por via marítima (Gómez Bellard e Vidal González, 200o; Arruda e Cardoso, 2013: 748-749).

Ao inventário das ocupações em gruta do Grupo A poderia eventualmente acrescentar-se o caso muito particular da gruta artificial de São Paulo 2, em Almada (Barros e Espírito Santo, 1997), não incluída no catálogo acima apresentado por corresponder a uma estrutura de origem antrópica. Com efeito, o estudo recente dos contextos sidéricos documentados no interior desta estrutura funerária pré-histórica (Lacueva, 2020) revela a existência de notáveis concomitâncias com o panorama material já comentado para as grutas do Grupo A, podendo levar a pensar num contexto funcional e cultual compartido.

A um Grupo B pertencem outras incidências (Gruta da Ponte da Laje, Furnas do Poço Velho) cuja interpretação funcional é mais problemática. Nestes casos verifica-se a predominância de elementos relacionados com a indumentária, sendo os materiais cerâmicos (ausentes de resto na Gruta da Ponte da Laje) diferenciados na sua natureza dos que se registavam nas grutas do Grupo A.

No caso das Furnas do Poço Velho, e como ficou dito, uma eventual utilização funerária de cariz pontual não pode ser descartada, podendo quiçá aproximar-se conceptualmente de uma série de reutilizações de espaços funerários pré-históricos ocorridas durante a Idade do Ferro do Sul de Portugal (cf. Gomes, 2or6; Costela Muñoz, 20I7). No caso da Ponte da Laje, contudo, os dados são demasiado limitados para tecer qualquer tipo de considerações funcionais.

Naturalmente, não deve obviar-se neste contexto a presença de elementos relacionados com a indumentária e o adorno corporal na Lapa da Cova, acima categorizada no Grupo A. Contudo, a própria natureza desses elementos, onde predominam os objectos mais propriamente de adorno, a sua excepcional riqueza, que bem pode levar a interpretá-los como oferendas, e a sua associação a um conjunto expressivo de grandes recipientes cerâmicos assimiláveis aos documentados nas outras grutas do Grupo A, justifica a sua inclusão nesse primeiro grupo.

Finalmente, a um Grupo $\mathrm{C}$ pertenceriam, pelo menos provisoriamente, todas aquelas ocorrências (Lapa da Figueira, Lapa das Janelas I, Forte do Cavalo A e Abrigos da Cara do Cabo) sobre as quais pouco ou nada se sabe, o que impede de momento uma correcta aferição da sua natureza funcional.

\section{O uso das grutas na Idade do Ferro da Baixa Estremadura no seu contexto regional e mediterrâneo}

Como se pode apreciar, dos três grupos definidos no apartado precedente o mais substancial e informativo é, sem dúvida, o Grupo A. Além disso, pela sua 
natureza destacada, as ocupações integradas neste grupo merecem algumas considerações adicionais, nomeadamente no que diz respeito ao seu enquadramento cultural e cultual.

Uma aproximação global a esse enquadramento deve ter em conta dois âmbitos particulares: por um lado, o uso das grutas na região durante o período precedente, o Bronze Final, e, por outro, o uso das grutas entre as comunidades do Mediterrâneo com as quais os grupos locais estabelecem estreitas relações durante o período em apreço, relações essas com claros reflexos nos materiais e nas próprias práticas documentadas nos contextos analisados.

Em relação ao primeiro destes âmbitos, deve sublinhar-se que nas regiões cársicas do Sul de Portugal durante as etapas finais da Idade do Bronze se verificou uma intensa utilização das grutas, geralmente associada também ela a práticas rituais e cultuais (Gomes e Calado, 2007).

As incidências deste período são particularmente abundantes na Baixa Estremadura onde, além do caso bem conhecido da Lapa do Fumo (cf. Cardoso, 1996), se documentam ocupações do Bronze Final nas também já mencionadas grutas da Ponte da Laje (Cardoso e Carreira, 1996), do Correio-Mor (Cardoso, I997-I998; Cardoso et alii, 2003), do Poço Velho (Carreira, I990-I992), do Fojo dos Morcegos (Marques, I97I) e em várias das da Serra de Montejunto (Gonçalves, I990-I992), bem como na Gruta da Pedra Furada I (Vila Franca de Xira) (Silva et alii, 20I4: I67 e figss. I5-I7) e nas do Cabeço do Castelo e da Cova da Moura (Torres Vedras) (Gomes e Calado, 2007: 152, com bibliografia).

Na maioria, se não mesmo na totalidade dos casos, os conjuntos do Bronze Final recolhidos nestas grutas compõem-se predominantemente de recipientes cerâmicos, parte significativa dos quais dotados de decoração de ornatos brunidos ( $c f$. Cardoso, 1996; 1998; Gomes e Calado, 2007: 150), passíveis de interpretação como recipientes de oferendas e libações e, de forma mais geral, como a parafernália associada a actividades de tipo religioso e cultual (Serrão, 1959: 347; Gomes e Calado, 2007).

Apesar da escassa incidência de materiais derivados do fundo tipológico local/regional nos contextos da Idade do Ferro antes inventariados, este precedente do
Bronze Final não parece de somenos importância, quer por oferecer um pano de fundo genérico para a sacralização das cavidades cársicas nesta região, quer pela aparente similitude das práticas documentadas em ambos os momentos. $\mathrm{O}$ facto de várias das grutas com ocupações do Bronze Final terem também conhecido ocupações na Idade do Ferro (Grutas do Correio-Mor e da Ponte da Laje, Furnas do Poço Velho, Lapa do Fumo) não parece também despiciendo.

No entanto, a tipologia e natureza dos materiais exumados nos contextos acima inventariados evidencia igualmente influências mediterrâneas que, tal como no contexto cultural mais geral das comunidades desta região, tiveram também um impacto substancial nas fórmulas rituais de utilização das grutas.

Neste contexto, não pode deixar de se sublinhar que em diversos âmbitos culturais do Mediterrâneo Antigo as grutas se revestiram de um forte significado religioso e cultual (Sporn, 20IO; 20I3; Stampolidis e Kotsonas, 2013), bem documentado, em particular, no âmbito fenício e, posteriormente, púnico (Gómez Bellard e Vidal González, 20oo; Marín Ceballos, 20Io: 231-232). Podem citar-se a este respeito exemplos tanto do Mediterrâneo Oriental (Gómez Bellard e Vidal González, 2000: I05-ıo6; Stampolidis e Kotsonas, 2006; Christian, 20I4) $\mathrm{CO}^{-}$ mo, sobretudo, do Mediterrâneo Central (Gómez Bellard e Vidal González, 2000: 106-ıо7).

Com a extensão da colonização fenícia, o uso sacro das grutas alcançou igualmente o Sul Peninsular, onde se destaca o caso do santuário de Gorham's Cave, em Gibraltar (Culican, 1972; Marín Ceballos, 2010: 230-232; Belén Deamos, 2010: 425-430; Belén e Pérez, 20II; Gutiérrez et alii, 20I2; 20I4), associado à sacralização das Colunas de Herácles. Outro possível exemplo situar-se-ia em Gadir, onde Avieno (Ora Maritima, 304-317) refere a existência de um santuário de Vénus, interpretatio da Astarté fenícia, aparentemente situado numa cavidade natural (Ferrer Albelda, 200I-2002: IIO-III). Por outro lado, não pode deixar de se citar neste contexto o importante santuário púnico de Es Cuieram, em Ibiza (Aubet, 1982; Marín Ceballos, Belén Deamos e Jiménez Flores, 2010).

Estes exemplos de grutas-santuário têm sido lidos à luz da relação espacial das cavidades cársicas em questão com o mar e, como acima se mencionou, com 
a prática da sacralização de acidentes geográficos relevantes, como ilhas, cabos e penínsulas, que constituiriam marcos importantes para a orientação da navegação (Gómez Bellard e Vidal González, 200o; vid. et. López-Sánchez, Niveau de Villedary y Mariñas e Gómez González, 2019).

Não pode por isso deixar de se assinalar, na esteira de outros autores (Arruda e Cardoso, 2013: 748-749), que os casos portugueses se poderiam enquadrar numa lógica semelhante. As grutas integráveis no Grupo A oferecem, de facto, uma relação geográfica estreita com o mar e situam-se em contextos orograficamente muito relevantes.

Com efeito, o Maciço da Arrábida interrompe a longa linha Norte-Sul da Costa Vicentina e sinaliza o acesso ao Estuário do Sado, dotado de boas condições portuárias, e as grutas da Península de Lisboa associam-se também elas ao amplo porto natural constituído pelo Estuário do Tejo, podendo mesmo

\section{Bibliografia}

AA.VV. (2009): O Tempo do Risco. Carta Arqueológica de Sesimbra. Sesimbra.

Arruda, A.M. (20I4): "A Oeste tudo de novo. Novos dados e outros modelos interpretativos para a orientalização do território português". Em A.M. Arruda (ed.): Fenícios e Púnicos, por Terra e Mar (2). Lisboa: $513-535$.

Arruda, A.M. (20I7): "A Idade do Ferro Orientalizante no Vale do Tejo: as duas margens de um mesmo rio". Em S. Celestino Pérez e E. Rodríguez González (eds.): Territorios comparados: los valles del Guadalquivir, el Guadiana y el Tajo en época tartésica. Madrid: 283-294.

Arruda, A.M., Barbosa, R., Gomes, F. e Sousa, E. de (2017): "A necrópole da Vinha das Caliças (Trigaches, Beja, Portugal)”. Em J.Jiménez Ávila (ed.): Sidereum Ana III: El río Guadiana y Tartessos. Mérida: I43-179.

Arruda, A.M. e Cardoso,J.L. (2013): "A ocupação da Idade do Ferro da Lapa do Fumo (Sesimbra)". Estudos Arqueológicos de Oeiras, 20: 731-754. a gruta da Rua da Judiaria associar-se, de certo modo, ao fundeadouro natural que existiria no período em causa no sopé da Colina do Castelo de Lisboa.

Considerados estes dois âmbitos, parece lícito levantar a hipótese de a utilização das grutas desta região durante a Idade do Ferro ter resultado, pelo menos numa etapa inicial, de uma confluência entre crenças e práticas de âmbito regional, com raízes no Bronze Final, com costumes e rituais de origem mediterrânea. Nesse sentido, as grutas - como de resto outros espaços de natureza sacra (cf. Gomes, 20I2) poderão ter actuado, se não como um espaço de encontro entre comunidades locais e exógenas, pelo menos como um middle ground sincrético onde as práticas sociais e religiosas sobrepostas de ambas poderão ter sido objecto de uma translação cultural que potenciaria o estabelecimento de relações sociais, políticas e económicas entre os vários agentes presentes na região.

Arruda, A.M., Freitas, V.T. e Vallejo Sánchez, J.I. (2000): "As cerâmicas cinzentas da Sé de Lisboa". Revista Portuguesa de Arqueologia, 3(2): 25-59.

Arruda, A.M., Sousa, E. de, Pimenta, J., Soares, R. e Mendes, H. (20I7): "Phéniciens et indigènes en contact a l'embouchure du Tage, Portugal". Em M. Guirguis (ed.): From the Mediterranean to the Atlantic: people, goods and ideas between East and West,. . Pisa/Rome: 243-25I.

Aubet, M.E. (1982): El santuario de Es Cueiram. Ibiza. Belén Deamos, M. (2010): "Itinerarios arqueológicos por la geografía sagrada del Extremo Occidente". Em M.C. Marín Ceballos (coord.): Cultos y ritos de la Gadir fenicia. Cádiz: 423-472.

Belén, M. e Pérez,I. (2010): “Gorham’s Cave, un santuario en el Estrecho. Avance del estudio de los materiales cerámicos". Em M.C. Marín Ceballos (coord.): Cultos y ritos de la Gadir fenicia. Cádiz: 473-489.

Calado, M., Gonçalves, L., Mataloto, R. e Jiménez Ávila, J. (2017): "Lapa da Cova: un santuario costero en los acantilados de Sesimbra (Portugal)". Em M. Martínez Alcalde, J.M. García Cano, J. Blánquez Pérez e A. Iniesta Sanmartín (eds.): Mazarrón II. Contexto, viabilidad y perspectivas del barco B-2 de la bahía de Mazarrón. Madrid: 525-543. 
Calado, M., Almeida, L., Leitão, V. e Leitão, M. (20I3): "Cronologias absolutas para a Ia Idade do Ferro em Olisipo - O exemplo de uma ocupação em ambiente cársico na actual Rua da Judiaria em Alfama”. Cira Arqueologia, II: II8-I32.

Cardito Rollán, L.M. (1996): "Las manufacturas textiles en la Prehistoria: las placas de telar en el Calcolítico Peninsular”. Zephyrus, 49: I25-I45.

Cardoso,J.L. (1995a): "Novas escavações na gruta da Ponte da Lage (Oeiras). Revisão dos materiais paleolíticos". Estudos Arqueológicos de Oeiras, 5: 49-66.

Cardoso,J.L.(1995b): “O santuário calcolítico da gruta do Correio-Mor (Loures)”. Estudos Arqueológicos de Oeiras, 5: 97-I2I.

Cardoso, J.L. (1996): "O Bronze Final da Baixa Estremadura e as cerâmicas de ornatos brunidos da Lapa do Fumo (Sesimbra)". Sesimbra Cultural, 5: 6-I4.

Cardoso, J.L. (1997-1998): "As cerâmicas de ornatos brunidos da gruta do Correio-Mor (Loures)". Estudos Arqueológicos de Oeiras, 7: 155-I67.

Cardoso, J.L. (2000): "Manifestações funerárias da Baixa Estremadura no decurso da Idade do Bronze e da Idade do Ferro (II e I milénios A.C.): breve síntese". Actas do $3^{\circ}$ Congresso de Arqueologia Peninsular, vol. 5. Porto: 61-1oo.

Cardoso,J.L. (2004): A Baixa Estremadura, dos finais do IV milénio a.C. até à chegada dos Romanos: um ensaio de História Regional. Oeiras.

Cardoso,J.L. (2013): "A necrópole campaniforme da gruta da Ponte da Lage (Oeiras): estudo dos espólios cerâmicos e metálicos e respectiva cronologia absoluta”. Estudos Arqueológicos de Oeiras, 20: 589-604.

Cardoso, J.L. (20I4): "A Sepultura Calcolítica da Gruta da Ponte da Laje (Oeiras)". Estudos Arqueológicos de Oeiras, 2r: 183-194.

Cardoso, J.L. e Carreira,J.R. (I996): "Materiais cerâmicos da Idade do Bronze da gruta da Ponte da Lage (Oeiras)". Estudos Arqueológicos de Oeiras, 6: $34 \mathrm{I}-350$.

Cardoso, J.L., Ferreira, O. da V., Zbyszewski, G., Leitão, M., North, C.T., Norton, J. e Berger, F. (2003): "A Gruta do Correio-Mor (Loures)". Estudos Arqueológicos de Oeiras, II: 229-32I.
Carreira,J.R. (I990-I992): "As ocupações das Idades do Bronze e do Ferro das Grutas do Poço Velho (Cascais)". O Arqueólogo Português, IV (8-זо): 229-245.

Celestino Pérez, S. e Jiménez Ávila, J. (1996): El Palacio-Santuario de Cancho Roano V-VI-VII. El Sector Oeste. Badajoz.

Christian, M.A. (20I4): "Mediterranean grottos and the Umm El-Amed: coastal shrines and regional inland temples". CIPOA, 2: 373-392.

Correia, V., Parreira, R. e Silva, A.C.F. da (2013): $\mathrm{Ou}_{-}$ rivesaria Arcaica do Território Português. Lisboa.

Costela Muñoz, Y. (2017): "La pervivencia de la ideología megalítica durante el II y I milenios a.n.e. Un caso de estudio: el sur de Portugal". Revista Portuguesa de Arqueologia, 20: 45-6o.

Culican, W. (1972): "Phoenician remains from Gibraltar". Australian Journal of Biblical Archaeology, I (5): IIO-I45.

Félix, P. (1993): "A região nabantina no final da Pré-história: algumas considerações acerca do estudo do povoamento do I milénio a.C.”. Boletim Cultural da Câmara Municipal de Tomar, 19: 239-254.

Ferreira, O.da V., Leitão, M.,Zbyszewski, G. e North, C.T. (1987): "O Paleolítico da gruta do Correio-Mor (Loures)”. Setúbal Arqueológica, 8: 7-27.

Ferrer Albelda, E. (200I-2): "La religión púnica en Iberia: lugares de culto". Estudios Orientales, 5-6: IO7-II9.

Gomes, F.B. (2012): Aspectos do Sagrado na Colonização Fenícia. Lisboa.

Gomes, F.B. (2016): Contactos culturais e discursos identitários na I Idade do Ferro do Sul de Portugal (séculos VIII - V a.n.e.): leituras a partir do registo funerário. Tese de Doutoramento em $\mathrm{Ar}-$ queologia apresentada à Faculdade de Letras da Universidade de Lisboa.

Gomes,F.B. (2018): "Fusayolas de la necrópolis de Olival do Senhor dos Mártires (Alcácer do Sal, Portugal): tipología, función y simbolismo". Sagvntvm, 49: 43-59.

Gomes, M.V. e Calado, D. (2007): "Conjunto de cerâmicas da gruta da Ladroeira Grande (Moncarapacho) e os santuários subterrâneos, da Idade do Bronze Final, no Sul de Portugal”. Revista Portuguesa de Arqueologia, IO(I): I4I-I58. 
Gómez Bellard, C. e Vidal González, P. (2000): "Las cuevas-santuario fenicio-púnicas y la navegación en el Mediterráneo". Em J. Fernández Gómez e B. Costa Ribas (coords.): Santuarios fenicio-púnicos en Iberia y su influencia en los cultos indigenas. Ibiza: 57-102.

Gonçalves, J.L.M. (1990-1992): "As grutas da Serra de Montejunto (Cadaval)". O Arqueólogo Português, IV(8-10): 4I-20I.

Gonçalves, V.S. (2008): As Ocupações Pré-Históricas das Furnas do Poço Velho (Cascais). Cascais.

Gutiérrez López,J.M., Reinoso del Río, M.C., Saéz Romero, A.M., Giles Pacheco, F. e Finlayson, C. (20I2): "Las ofrendas de Hannón. El santuario de Gorham's Cave (Gibraltar) y la navegación cartaginesa atlántico-mediteránea”. Em M.B. Cocco, A. Gavini e A. Ibba (eds.): L'Africa Romana. Trasformazione dei paesaggi del potere nell'Africa settentrionale fino alla fine del mondo antico. Vol. 3. Sassari: 2955-2970.

Gutiérrez López,J.M., Reinoso del Río, M.C., Saéz Romero, A.M., Giles Pacheco, F., Finlayson, C. e Zamora López, J.A. (20I4): "El santuario de la Cueva de Gorham (Gibraltar). Estado de la cuestión (con la presentación de un nuevo grafito fenicio)". CIPOA, 2: 619-629.

Jiménez Ávila, J. (2013): “«Braseros» de bronce protohistóricos en Extremadura. Viejos y nuevos hallazgos; nuevas y viejas ideas". Onoba, r: 55-78. Jiménez Ávila,J.,Mataloto, R., Calado, M.e Gonçalves, L. (20I8): "Lapa da Cova (Sesimbra, Portugal): a coastal sanctuary on the western border of the Mediterranean". Em M. Guirguis, (ed.): From the Mediterranean to the Atlantic: people, goods and ideas between East and West, 2. Pisa/Rome: 309-316.

Lacueva, C. (2020): A ocupação da Idade do Ferro da gruta artificial de São Paulo 2 (Almada). Tese de Mestrado em Arqueologia apresentada à Faculdade de Letras da Universidade de Lisboa.

López Sánchez, N., Niveau de Villedary y Mariñas, A.M. e Gómez-González, J.I. (2org): “The Shrines of Gadir (Cadiz, Spain) as References for Navigation. GIS Visibility Analysis". Open Archaeology, 5: 284-308.

Lorrio, A. (2008): "Cuchillos". Em M. AlmagroGorbea (dir.): La necrópolis de Medellin. II. Estudio de los hallazgos. Madrid: 566-571.
Marques, G. (1971): "Fojo dos Morcegos - Assafora (Sintra)". Actas e Memórias do I Congresso Nacional de Arqueologia, Vol. I. Lisboa: 337-359.

Marín Ceballos, M.C. (2010): "Santuarios prerromanos de la costa atlántica andaluza”. Em S. Celestino Pérez, T.Tortosa e R. Cazorla Martín (eds.): Debate en torno a la religiosidad protohistórica. Madrid: 219-243.

Marín Ceballos, M.C., Belén Deamos, M. e Jiménez Flores, A.M. (2010): "El proyecto de estudio de los materiales de la cueva de Es Culleram". Mainake, 32(I): 133-157.

Mayet, F. e Silva, C.T. da (2000): L'établissement phénicien d'Abul, Portugal. Paris.

Negueruela, I. (I979): "Sobre la cerámica de engobe rojo en España”. Habis, X-XI: 335-359.

Oliveira, A.C., Silva, A.R., Deus, M. de e Estevão, F. (2000): Carta Arqueológica do Município de Loures. Loures.

Pellicer, M. (1978): “Tipología y cronología de las ánforas prerromanas del Guadalquivir según el Cerro Macareno (Sevilla)". Habis, IX: 365-40o.

Pereira,T.R.(2013): "Por um fio: tipologia e função do conjunto de cossoiros de Cabeça de Vaiamonte (Monforte/Portugal)". Em J.M. Arnaud, A. Martins e C. Neves (eds.): Arqueologia em Portugal: 150 anos. Lisboa: 68I-69I.

Ramon Torres, J. (1995): Las Ánforas Fenicio-Púnicas del Mediterráneo Central y Occidental. Barcelona.

Rufete Tomico, P. (1988): “Las cerámicas con engobe rojo de Huelva". Huelva Arqueológica, X-XI: II-40.

Serrão, E. da C. (I96I): "Cerâmica proto-histórica da Lapa do Fumo (Sesimbra) com ornatos coloridos e brunidos”. Zephyrus, 9 (2): I77-I86.

Serrão, E. da C. (1975): "Contributos arqueológicos do sudoeste da península de Setúbal”. Setúbal Arqueológica, 1: 199-225.

Serrão, E. da C. (1994): Carta Arqueológica de Sesimbra. Sesimbra.

Serrão, E. da. C. e Marques, G. (1971): "Estrato précampaniforme da Lapa do Fumo (Sesimbra)". Actas do II Congresso nacional de Arqueologia. Coimbra: I2I-I42.

Silva, A.M., Boaventura, R., Pimenta, J., Detry, C.e Cardoso, J.L. (20I4): "Perscrutando espólios antigos: a Gruta de Pedra Furada I (Vila Franca de Xira)". Estudos Arqueológicos de Oeiras, 2I: 159-182. 
Silva, C.T. da (2005): "A presença fenícia e o processo de Orientalização nos Estuários do Tejo e do Sado". Em S. Celestino Pérez e J. Jiménez Ávila (eds.): El Periodo Orientalizante. Madrid: 749-766.

Silva, C.T. da, Soares, J., Beirão, C. de M., Dias, L.F.e Coelho-Soares, A. (I980-I): "Escavações arqueológicas no Castelo de Alcácer do Sal (campanha de 1979)". Setúbal Arqueológica, 6-7: 149-218.

Sousa, E. de (20I4): A Ocupação Pré-Romana da Foz do Estuário do Tejo. Lisboa.

Sousa, E. de (2015): "The Iron Age occupation of Lisbon”. Madrider Mitteilungen, 56: 109-г38.

Sousa, E. de (2016): "A Idade do Ferro em Lisboa: Uma primeira aproximação a um faseamento cronológico e à evolução da cultura material". CuPAUAM, 42: 167-I85.

Sousa, E. de e Arruda, A.M. (2018): "A I Idade do Ferro na Alcáçova de Santarém (Portugal): os resultados da campanha de 2001". Onoba, 6: 57-95.

Sousa, E. de e Pimenta,J. (20I4): "A produção de ânforas no Estuário do Tejo durante a Idade do Ferro". Em R. Morais, A. Fernández e M.J. Sousa (eds.): As produçôes de imitação na Hispania. Porto: 303-316.
Sporn, K. (2010): "Espace naturel et paysages religieux: les grottes dans le monde grec". Revue de l'bistoire des religions 4: 553-571.

Sporn, K. (2013): "Mapping Greek Sacred Caves: Sources, Features, Cults”. Em F. Mavridis e J.T. Jensen (eds.): Stable Places and Changing Perceptions: Cave Archaeology in Greece. Oxford: 212-216.

Stampolidis, N. e Kotsonas, A. (2006): "Phoenicians in Crete". Em S. Deger-Jalkotzy e I. Lemos (eds.): Ancient Greece from the Mycenaean Palaces to the Age of Homer. Edimburgo: 337-36o.

Stampolidis, N. e Kotsonas, A. (2013): "Cretan Caves Sanctuaries of the Early Iron Age to the Roman Period".Em F.Mavridis e J.T.Jensen (eds.): Stable Places and Changing Perceptions: Cave Archaeology in Greece. Oxford: 188-200.

Tente, C. e Lourenço, S. (20I6): "A ocupação da Idade do Ferro da Galeria da Cisterna (sistema cársico da Nascente do Almonda, Torres Novas)". Revista Portuguesa de Arqueologia, I9: I43-I54.

Zbyszewski, G., Ferreira, O.V. e Viana, A. (1957): "A gruta pré-histórica da Ponte da Laje (Oeiras)". Comunicaçôes dos Serviç̧os Geológicos de Portugal, 38(2):389-400. 